\title{
Green Certificates and Emission Trading
}

Fristrup, Peter

Publication date:

2002

Document Version

Publisher's PDF, also known as Version of record

Link back to DTU Orbit

Citation (APA):

Fristrup, P. (Ed.) (2002). Green Certificates and Emission Trading. Risø National Laboratory.

\section{General rights}

Copyright and moral rights for the publications made accessible in the public portal are retained by the authors and/or other copyright owners and it is a condition of accessing publications that users recognise and abide by the legal requirements associated with these rights.

- Users may download and print one copy of any publication from the public portal for the purpose of private study or research.

- You may not further distribute the material or use it for any profit-making activity or commercial gain

- You may freely distribute the URL identifying the publication in the public portal

If you believe that this document breaches copyright please contact us providing details, and we will remove access to the work immediately and investigate your claim 


\section{Green Certificates and Emission Trading}

Edited by Peter Fristrup

Systems Analysis Department

Risø National Laboratory, Roskilde December 2002 


\section{Abstract}

This report provides a number of results on the interaction between an international market for green certificates market and other energy and environmental policies. The main conclusion is that the deployment of RES-E is likely to be achieved without extra consumer cost through proper use of both Tradable Green Certificates and Tradable Emission Permits. Using these policy instruments in concerted action, the cost of deployment will most likely be financed through profit reduction at conventional power plants.

Print: Pitney Bowes Management Services Denmark A/S, 2002 


\section{Preface}

This is the final report on a research project on "Interaction between an international green certificate market and other environmental policies." The research was conducted with participant from six Danish organisations: Elkraft, Eltra, Risø National Laboratory, the Association of Danish Energy Producers and the University of Southern Denmark. This report is a condensed presentation of the main results from the research project.

In September 2001 the project group hosted an international workshop with 40 participants from 8 European countries. A special issue of Energy Policy (Energy Policy Vol 31(1)) has been devoted to this workshop. Contents of this issue (project members are indicated by a ${ }^{*}$ ):

- Preface: Green certificates and emission trading by P.E. Morthorst*, K. Skytte* and P. Fristrup*

- L. Nielsen* and T. Jeppesen*: Tradable Green Certificates in Selected European Countries - Overview and Assessment.

- P. Fristrup*: Some challenges related to introducing tradable green certificates.

- J. Lemming*: Financial Risks for Green Electricity Investors and Producers in a Tradable Green Certificate Market.

- A. Lorenzoni: The Italian Green Certificates Market - Between uncertainty and opportunities.

- M. Boots: Green certificates and carbon trading in the Netherlands

- A. Varma: UK's Climate Change Levy: Cost-effectiveness, competitiveness and environmental impacts.

- K. Skytte* and S.G. Jensen*: Simultaneous attainment of energy goals by means of green certificates and emission permits.

- P.E. Morthorst*: National environmental targets and international emission reduction instruments.

- H. Ravn* et al.: Co-existence of Electricity, TEP and TGC markets in the Baltic Sea region.

The writing style of the report is a focused tutorial, presenting the results from the project research as a series of short expositions each containing a minor or major result on the research topic. The two terms electricity and power will be used interchangeably though electricity is the preferred term in this report.

Further to this special issue the research project participants have produced a number of publications and presentations. A list of total production from this project will be found at page 48.

The research project was supported with research grant (EFP2000-1753/00-0016) from the Danish Energy Authority's Energy Research Programme. 


\section{Table of Contents}

\section{Preface 3}

\section{Table of Contents 4}

\section{Introduction 6}

The microeconomics basics of the deployment of renewable energy 8

Exposition \# 1: Self-deploying RES-E in a single country 8

Exposition \# 2: Inducing deployment of RES-E by investment subsidies 9

Exposition \# 3: Inducing deployment of RES-E by price subsidies 10

Exposition \# 4: Introducing energy taxes 11

Exposition \# 5: Introducing $\mathrm{CO}_{2}$ taxes 11

Exposition \# 6: Introducing tradable emission permits 12

\section{The impact of international trade 14}

Exposition \# 7: Deploying RES-E in a group of countries 14

Exposition \# 8: Introducing internationally Tradable Green Certificates 15

Exposition \# 9: Facilitating deployment with both TEPs and TGCs 16

\section{Using TGCs as a policy instrument 18}

Exposition \# 10: Short run RES-E supply 18

Exposition \# 11: Long run RES-E supply 19

Exposition \# 12: Fine tuning with TGCs 19

\section{Electricity as a composite commodity 21}

Exposition \# 13: Engagement in three markets 21

Exposition \# 14: Price regimes and instrument redundancy 23

Exposition \# 15: Welfare analysis 23

Exposition \# 16: A renewable energy goal with two regulatory instruments 25

Exposition \# 17: An emission goal supported by two regulatory instruments 26

Exposition \# 18: Two goals and two instruments 27

Exposition \# 19: Alternative overall objectives 29 
The international aspect of TGCs 30

Exposition \# 20: The RECS certificate system 30

Exposition \# 21: Technologies eligible for certificates 31

Exposition \# 22: Mechanisms for market stabilisation 32

Exposition \# 23: Mechanisms for initiating demand 33

Exposition \# 24: Coexisting regulatory schemes directed at renewable energy 33

Exposition \# 25: A common European market for TGCs 34

Financial risk in the TGC market 35

Exposition \# 26: Price setting 36

Exposition \# 27: Short term financial risk 38

Exposition \# 28: Forward contracts and risk premia 39

A case study: Combining international markets $\mathbf{4 0}$

Exposition \# 29: Modelling Bubbles and Markets 40

Exposition \# 30: Scenarios in the Balmorel model 41

Exposition \# 31: National implications 44

Exposition \# 32: Welfare Analysis 45

Policy implications of TGCs 46

\section{References 47}

Publications from the research project 48 


\section{Introduction}

Through the last three decades Danish energy policy has moved from a main focus on the security of fuel supply to a focus on $\mathrm{CO}_{2}$ abatement in a liberalised power supply sector. Rigid rules such as compulsory combined heat and power (CHP) production have been accompanied by economic incentives, such a $\mathrm{CO}_{2}$ taxes, and investment subsidies and fixed feed-in tariffs for electricity from renewable energy sources (RES-E).

Contemporary Danish energy policy objectives are subject to reconsideration due to a shift in government. Most policies will though be close to the description in Danish Energy Authority (2001):

- Climate objectives, including a fulfilment of the national target of a $20 \%$ reduction of $\mathrm{CO}_{2}$ emissions in 2005 related to 1998 through a continued development and deployment of wind turbines and CHP. Furthermore, Denmark will ratify the Kyoto protocol.

- Security of supply, to ensure that efficient handling of output problems and the utilisation of reserve capacity are not jeopardised in order to obtain economic efficiency and emissions reductions.

- The accelerated liberalisation in the EU contains elements such as full market access for all consumers, unbundling, third-party access, cross-border exchange and other. These issues will not be allowed to suppress security of supply and environmental considerations.

- The electricity supply will be subject to market mechanisms in such a way that Denmark can continue to pursue the environmental objectives for the electricity sector. Furthermore, Danish power plants are now subject to a $\mathrm{CO}_{2}$ emission quota scheme grandfathering tradable emission permits to the plants at a falling rate.

- The green electricity market was supposed to put an end to the RES-E fixed feed-in tariff scheme and to enhance the economic efficiency in RES-E by the introduction of tradable green certificates (TGCs). The TGC scheme would be less beneficial to producers and thus stall the deployment of RES-E for a period.

- The Renewable Energy Directive as described by European Commission (2001) contains definitions of RES-E and TGCs; a portfolio of conceivable support schemes; and a indication of national targets for future consumption of electricity produced from renewable energy sources in terms of a fraction of electricity consumption. The Danish target is $29 \%$ in 2010 .

- The gas supply will follow the EU gas directive implying the Danish gas marked to be gradually opened. By public ownership of the gas infrastructure and by proper unbundling of the trading subject to competition, both security of supply and appropriate exploitation of the gas will supported in an open marked.

- Open-field plants and other small-scale CHP plants have proven to be high cost heat suppliers. Aid schemes will be developed to relief the heat consumers from some of these cost.

- Energy consumption has reached an almost constant level, but will still need attention. As a part of fulfilling the long-term energy and environmental goals the consumption has to be reduced to improve emissions and to improve security of supply.

- Research \& Development. It is recognised that research in and development of technology with a high energy efficiency are essential to energy savings and to increase the share of renewable energy. 
- Oil and Gas production in Denmark is at a raising trend thus contributing to an improvement of the balance of payments. The extraction of oil and gas is expected to continue for many years to come.

Further to the specific energy and environmental goals specified above it should be noted that domestic generation of electricity generates jobs and demand for Danish resources such as bio-fuels. This report will focus on only some of the issues above, mainly the coexistence of TGCS and TEPs; incentives to RES-E deployment; and the market implications of incentives to RES-E deployment.

Prior to the formal economic analysis of the deployment of renewable energy some general points about the implications of RES-E policies should be made:

First, RES-E is emission free. Economic growth can thus be sustained through RES-E without jeopardising the green house gas emission targets.

Second, the deployment of RES-E enhances production capacity thus leading to more fierce competition resulting in lower electricity prices at margin and hence possibly also an increase in electricity consumption. RES-E would never be expected to fully substitute nonRES-E.

Third, the introduction of RES-E provides a further diversification of fuels in electricity generation and an increase in the level of energy self supply leading to a relaxation of the relation between electricity prices and world market fuel prices.

Fourth, some types of RES-E, such as electricity originating from wind or solar energy, are highly dependable on local weather conditions and hence very unreliable with regard to security of supply. Offsetting technology must exist such as power plants or energy storage. Electrons from such uncontrollable RES-E sources are of course of less value to the market than the electrons originating from a controlled dispatch.

Fifth, although water is a naturally recurring domestic product, hydropower is often being considered to be non-renewable. This renunciation of hydropower relates to the fact that much of the contemporary discussion of RES-E relates to new deployment of generation capacity only.

Sixth, nuclear power is although green house gas emission free also not considered being RES-E. 


\section{The microeconomics basics of the deployment of renewable energy}

It is not clear-cut what will happen to the production of non-renewable energy on a liberalised market for power when the RES-E makes its entry. The analysis to follow will shed light on some of the pitfalls related to an energy policy with strong emphasis on both liberalisation and renewables.

\section{Exposition \# 1: Self-deploying RES-E in a single country}

Consider for the sake of simplicity a bounded power market with an existing stock of only non-RES-E. Figure 1 below shows a hypothetical supply and a demand curve with a resulting market price. When potential producers of RES-E consider deployment they relate the expected average cost of producing RES-E to these market conditions.

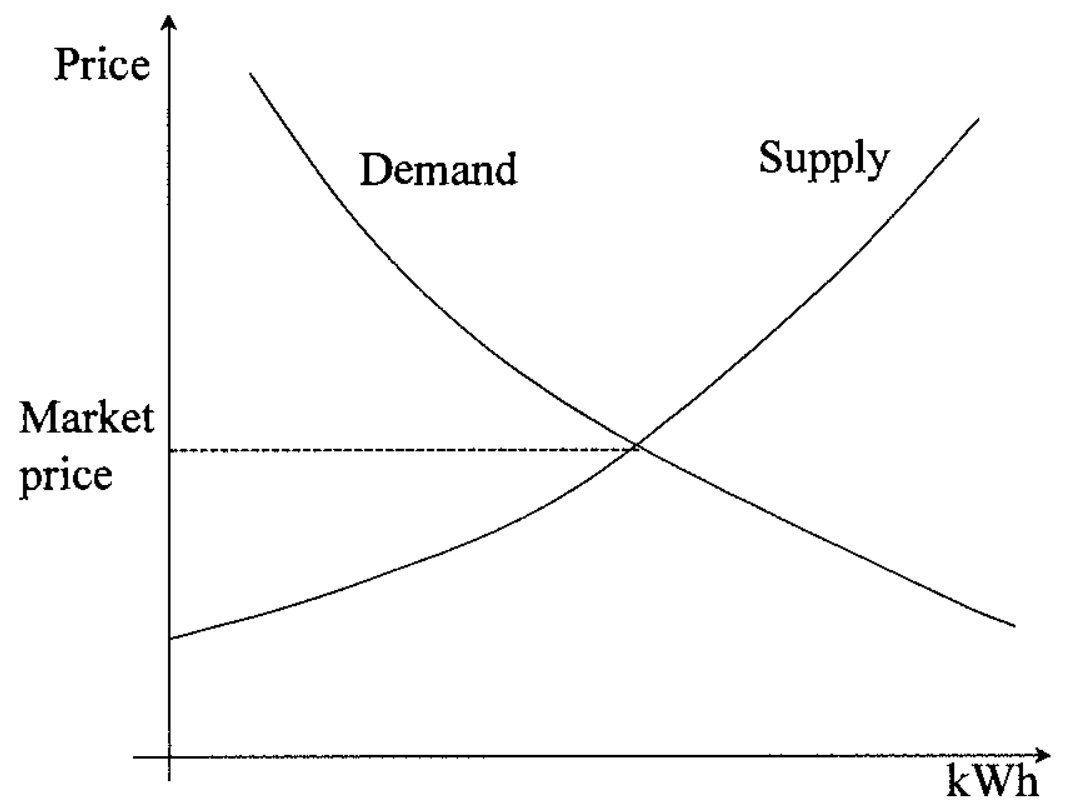

Figure 1. Demand and supply determines the power market price.

If RES-E should enter at market conditions it is required that the expected market price is higher that the average cost of supplying RES-E (including investment cost). In Figure 2 the entry of RES-E is illustrated by the horizontal part of the supply curve. The RES-E supply curve is truly upwards sloping, but the horizontal representation will not blur the analytical results, and will further make it easier to detect the RES-E part of the electricity supply. Market equilibrium with RES-E is reached at a lower price than before. Some of the existing stock of power plants have reduced their production resulting in a reduction of GHG emissions. These plants will be those that were marginal before, but with a cost above the new market price. 


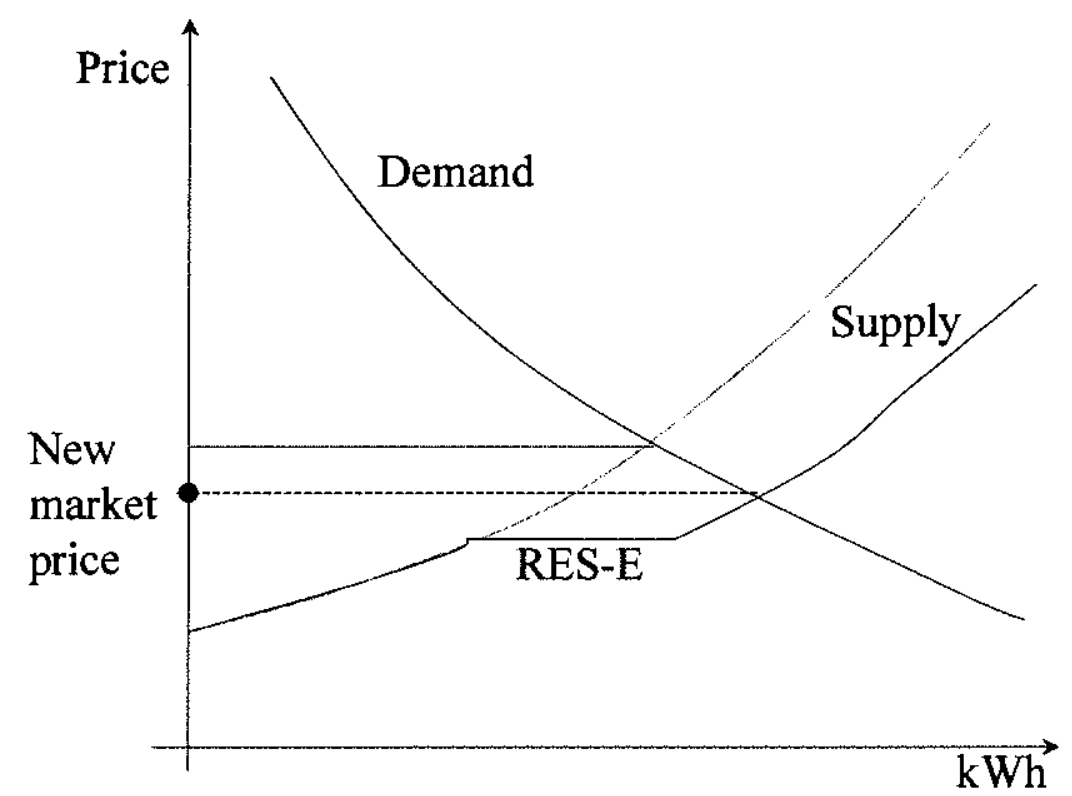

Figure 2. Deployment of RES-E (the horizontal segment) alters both price and quantity.

In Figure 2 the RES-E in not fully crowding out the existing technology, since the lowering of the supply curves results in market equilibrium with a lower price but with a higher overall consumption. Nevertheless, all suppliers with a cost higher than the new market price have been deterred from the market. This deterrence still implies some reduction of the greenhouse gas emissions.

\section{Exposition \# 2: Inducing deployment of RES-E by investment subsidies}

RES-E is yet not competitive at current power market prices. To promote RES-E either investment subsidies; price subsidies; or both will be needed. If the marginal cost of the RES-E technology is below expected market price, an investment subsidy would suffice, and the resulting power market could look like Figure 3.

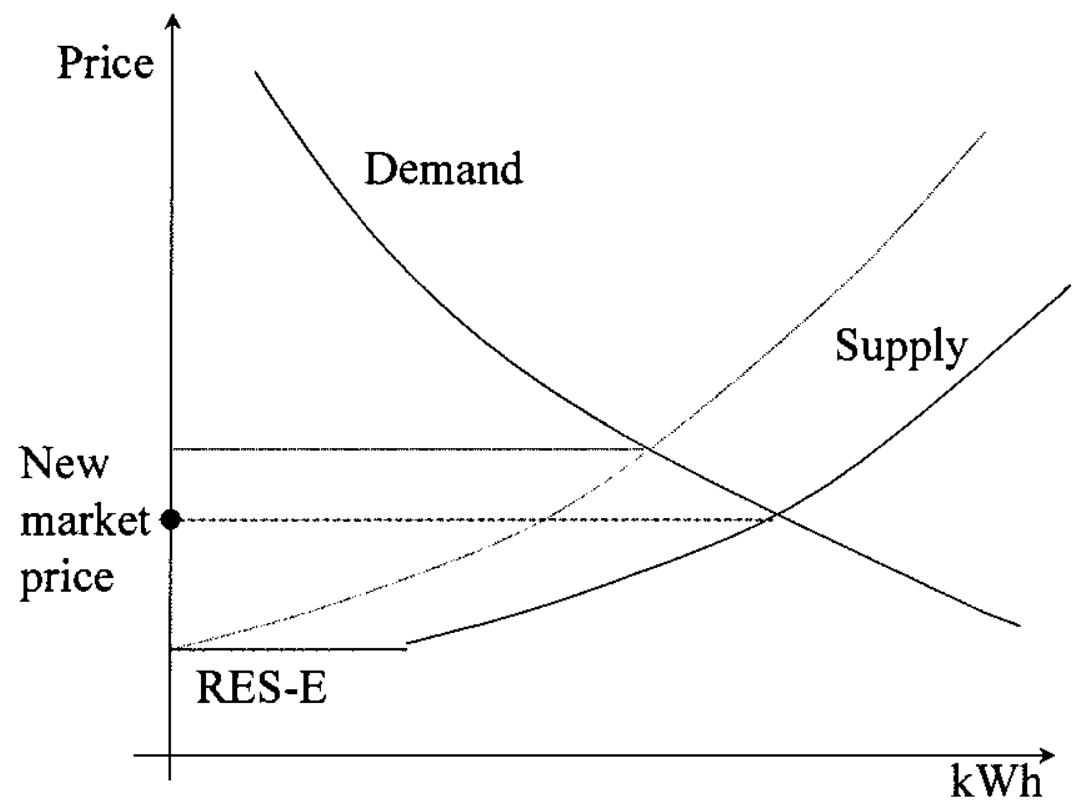

Figure 3. Investment subsidies reduce the required income to RES-E. 
Notice two things. First, the marginal cost of RES-E in the figure is arbitrarily chosen. The only assumption is that it is below market price. Second, the RES-E technology is the same as in Exposition \#1. The only difference is that investment cost is omitted from the calculations. The market result is also the same as before.

In Denmark, most of the existing stock of RES-E are priority dispatchers which means that no matter their marginal cost, they will always be the first to serve. Since electricity generation from solid waste incineration has lower cost than even wind turbines, the horizontal part of the supply curve will be positioned above the starting point of the curved part. This will have no impact on the market price, since the marginal cost of RES-E is expected to be less than the market price.

The fact that RES-E suppliers in Denmark are priority dispatchers allows the scenario, that the cost of RES-E - both marginal and average cost - is situated above the demand curve. The electricity market will thus have two equilibria: one with only (a part of) RES-E suppliers active on the market, and one with an equilibrium similar to the equilibrium in Figure 3.

\section{Exposition \# 3: Inducing deployment of RES-E by price subsidies}

If the deployment of RES-E is supported by price subsidies from the consumers, the same consumers will face an upward shift in the supply curve. Figure 4 depicts such a scenario where the cost of the subsidies is distributed over all power consumption. At a low consumption level the excess cost of the RES-E will have a large impact on power prices. This impact diminishes as the consumption grows. In the figure it is assumed that the price subsidy is the same for all RES-E production. The subsidy will cause a demand reduction that leads to further emission reduction.

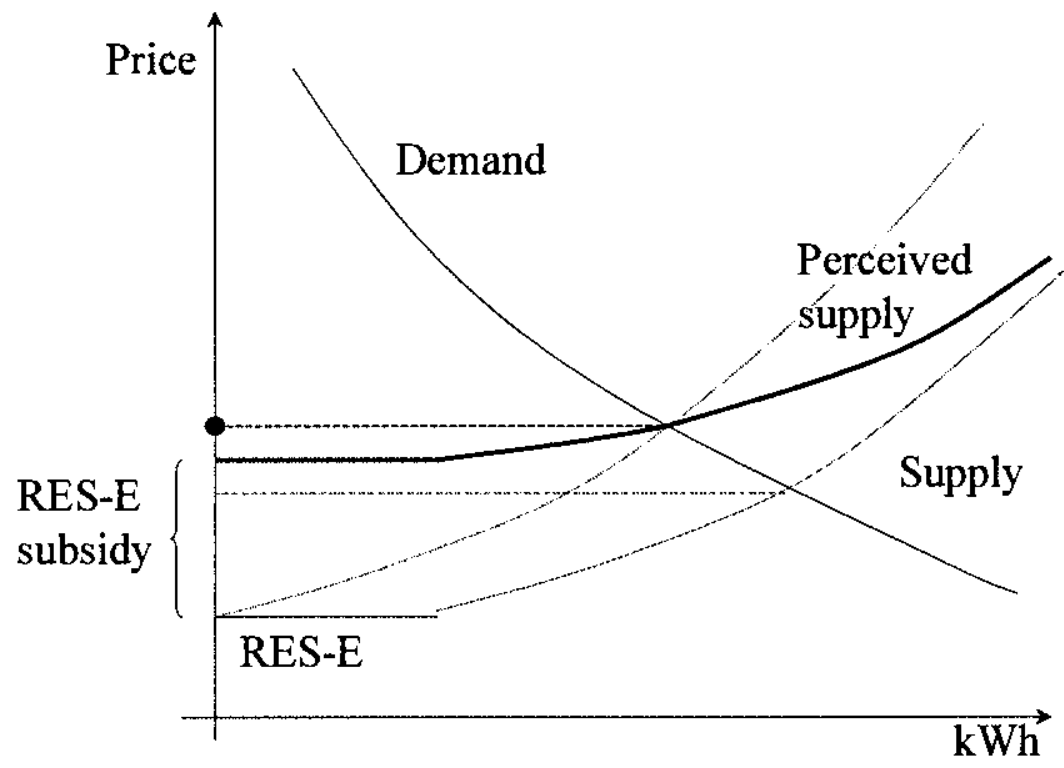

Figure 4. A mandatory price subsidy on RES-E will raise the perceived supply curve.

The RES-E subsidy equilibrium in the figure illustrates some interesting characteristics of the subsidy as a policy instrument. First, it is possible to obtain the market equilibrium existing prior to the deployment of RES-E. In this case the RES-E fully crowds out the less desired technologies. Second, the RES-E subsidy is not fully appropriated by the RES-E producers, since the increase in the equilibrium price induced by the subsidy will be less the size of the subsidy. Only when RES-E meets the full demand, will the price increase equal the subsidy. 
Also, the positioning of the RES-E part of the supply curve does not change the equilibrium in the analysis as long as the equilibrium contains electricity from non-renewable sources.

It should be noted that even a price subsidy in disguise, such a tradable green certificates, would influence the market equilibrium in the same way as long as the extra cost is distributed over all power consumption. The tradable green certificates will be discussed in the next section.

\section{Exposition \# 4: Introducing energy taxes}

An introduction of any type of penalty payment on the emission of green house gasses would expectedly increase the generation cost for most of the non-renewable power production. Figure 5 shows the impact of a fixed energy tax on non-RES-E.

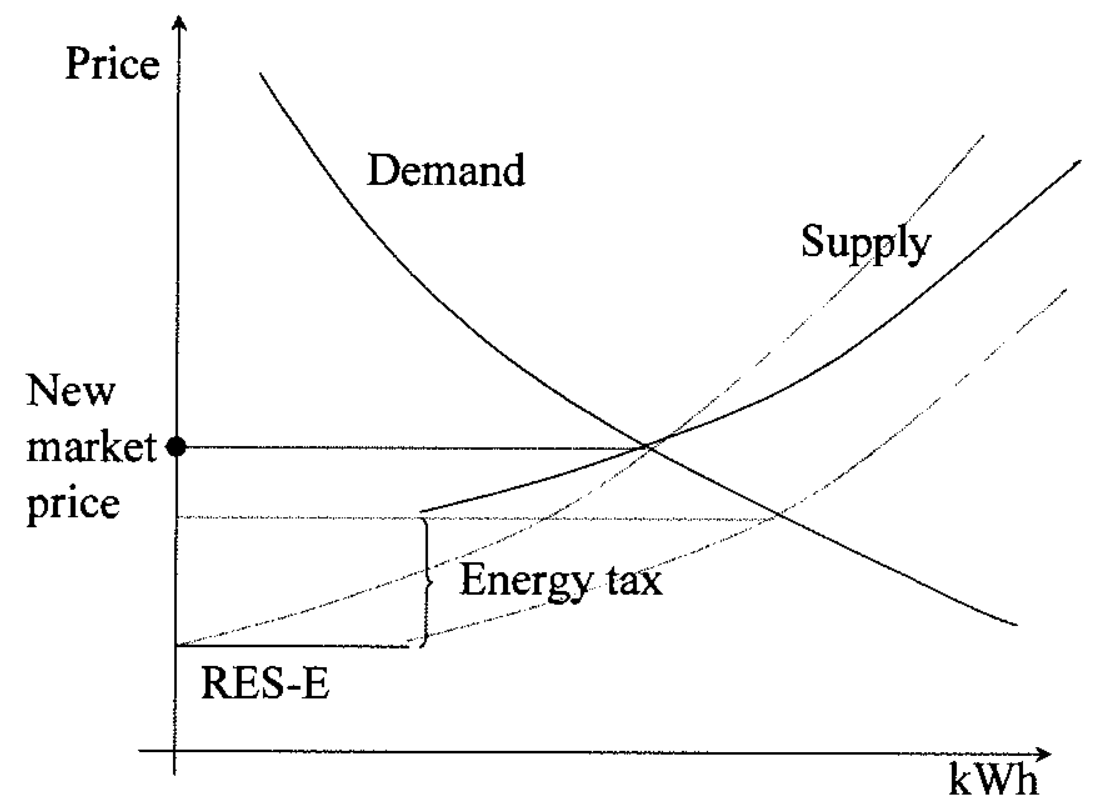

Figure 5. Imposing an energy tax on non-RES-E.

The figure indicates that through a proper choice of energy tax the original market price can be restored implying that all new RES-E will replace existing plants implying a reduction of emissions. This way of emission reduction is cost efficient since plants are superseded according to a trade-off between their production cost and their emissions at market prices. Plant are not selected according to their emissions, hence higher emission reductions might be possible at higher prices.

\section{Exposition \# 5: Introducing $\mathrm{CO}_{2}$ taxes}

To induce a proper cost efficient emission reduction it will be necessary to relate the energy taxes directly to the emissions and to charge these taxes directly to the plants. A tax in full accordance with the emission will change the cost rankings of the plants and thus impose a chance on the supply curve by moving the curve upwards and by changing the steepness of the curve. In a scenario with coal fired plant as low cost generators and natural gas plants as high cost generators the supply curve will become less steep, since the emissions tax will be higher on coal than on natural gars. Figure 6 illustrates the effects of an effective $\mathrm{CO}_{2}$ replacing as much emission as possible at a given price level. The dotted curve intersecting the word Supply is the original pre-RES-E supply curve. The lower dotted curve is the supply 
curve after the introduction of RES-E. In the new equilibrium, where the Demand and Supply curves intersect, pre-RES-E price has been re-established, but with a higher emission deterrence than with the energy tax.

No plant with a direct generation cost (ex tax) higher that the new equilibrium price would be candidates for supply. This means that the tax scheme in Figure 6 will never select supply technologies not serving the market prior to the deployment of RES-E, thus limiting the scope for emission reductions. The lower the level of the tax the smaller is the set of candidates for supply.

All plants differ on their production cost and emission taxes. In order to achieve maximal deterrence of emissions the taxes have to be high enough to alter the ranking of plants on the supply curve in order to promote some of the high cost low emissions plants. To achieve the selection of low emission suppliers the tax will possibly have to be very high implying also a very high electricity price which will be an unwanted effect on all other markets.

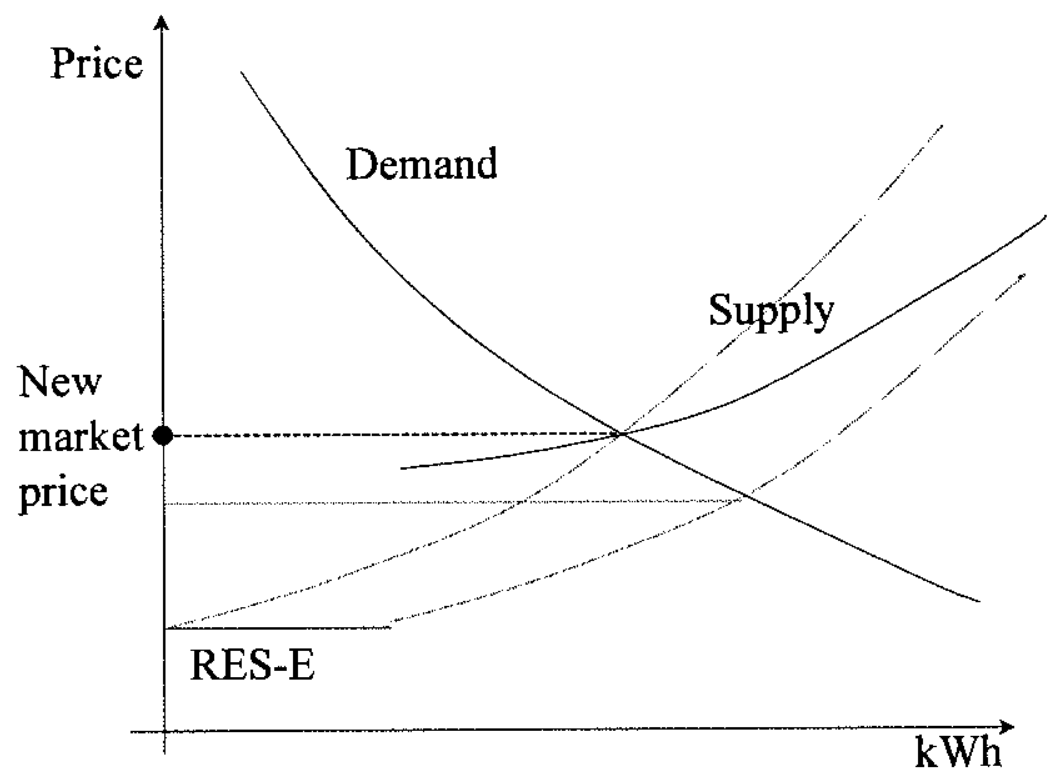

Figure 6. Restoring market equilibrium by applying an appropriate $\mathrm{CO}_{2} \operatorname{tax}$.

Further to the problems of only second-best solutions to the emission reduction problem the energy authorities will face a difficult in setting the right level of the $\mathrm{CO}_{2}$ tax. Setting the tax too low narrows the selection of suppliers and reduces the equilibrium price of electricity leading to an increase in demand. On the contrary, a high tax will improve the selection of suppliers but increase the market price in excess of the situation prior to the deployment of RES-E.

\section{Exposition \# 6: Introducing tradable emission permits}

In stead of setting a tax level the energy authorities could choose to set an aggregated emission level, an emission quota. This quota could then be divided into fractions - tradable emission permits (TEPs) - allowing the holder of such a permit to emit the amount stated on the permit. By auctioning the permits a market value of permits would be established. The ranking of the suppliers will be altered exactly as in the case with the emission tax. If the quota is too small the value of the permits will increase and improve the selection of suppliers and visa versa. 
There is no economic advantage of permits over taxes. But the political value is quite substantial. First, if climate policy goals are stated in quantities then the energy authority needs no further information to regulate electricity generation. Second, the price on TEPs is by definition not a tax but mere a rent related to a scarce commodity. Third, it is politically preferable not to impose taxes on a liberalised electricity market.

Some countries have chosen to distribute the TEPs to power plants at no cost according to a rationing scheme. If the permits are not tradable, they will not improve efficiency in emission reduction. If a holder of a TEP is free to trade it, two scenarios can occur. First, if the aggregated quota is not binding, the TEPs will have no value and the equilibrium is found as in Figure 3 . Second, if the aggregate quota is binding the equilibrium will be as described in the beginning of this exposition. 


\section{The impact of international trade}

Morthorst (2003) contains an analysis of a simple trading model with three countries and tree commodities, electricity, TGCs and TEPs. The commodities will be successively introduced through the following expositions.

\section{Exposition \# 7: Deploying RES-E in a group of countries}

Following Morthorst $(2001,2003)$ the consequences of uncoordinated national deployment of renewable energy might lead to unintended export of free emission reduction to trading partners on the electricity markets. The summary of the initial electricity generation configuration is described in Table 1 below.

\begin{tabular}{|c|c|c|c|c|c|c|c|}
\hline Country & RES-E & $\begin{array}{l}\text { Conven- } \\
\text { tional } \\
\text { electricity }\end{array}$ & $\begin{array}{c}\text { Electricity } \\
\text { demand }\end{array}$ & $\begin{array}{c}\text { Electricity } \\
\text { export }\end{array}$ & $\begin{array}{l}\text { Electricity } \\
\text { spot price }\end{array}$ & $\begin{array}{c}\mathrm{CO}_{2^{-}} \\
\text {emissions }\end{array}$ & $\begin{array}{c}\text { Initial } \\
\mathrm{CO}_{2-} \\
\text { emission } \\
\text { coefficients }\end{array}$ \\
\hline & TWh & TWh & TWh & TWh & $\mathrm{c} € / \mathrm{kWh}$ & MT/year & $\mathrm{Kg} / \mathrm{kWh}$ \\
\hline A & 4.0 & 39.8 & 40 & 3.8 & 3.0 & 35.8 & 0.90 \\
\hline B & 5.0 & 34.4 & 46 & -6.6 & 3.0 & 29.2 & 0.85 \\
\hline $\mathrm{C}$ & 6.0 & 30.8 & 34 & 2.8 & 3.0 & 24.6 & 0.80 \\
\hline Total & 15.0 & 105.0 & 120 & 0.0 & & 89.7 & 0.85 \\
\hline
\end{tabular}

Table 1: The initial pre-TGC and pre-TEP situation in the three countries.

(Source: Morthorst (2003))

All three countries have both RES-E and electricity generated from fossil fuels. The countries are assumed to have increasing marginal cost in electricity generation. The plants and hence the CO2-coefficients are different for each country. The calculations also assume that aggregated electricity consumption is inelastic, leaving aggregated electricity unchanged despite excess generation capacity.

Country $\mathrm{C}$ has the lowest emission coefficient and the lowest emissions but is still eager to reduce the emissions further by deploying a substantial amount of RES-E (37\% added). Together the three countries deploy 2.7 TWh of RES-E. Country C deploys more than $80 \%$ of this. The new electricity market is described in Table 2 below. RES-E is assumed to be subject to priority dispatch and since aggregated electricity consumption is assumed to be constant the conventional generation is reduced by the quantity of RES-E deployed. The change in equilibrium is depicted in Figure 7 where supply curves move to the right due to the deployment of RES-E.

\begin{tabular}{|c|c|c|c|c|c|c|c|c|}
\hline Country & $\begin{array}{c}\text { Increase } \\
\text { in RES-E }\end{array}$ & $\begin{array}{c}\text { RES-E } \\
\text { in total }\end{array}$ & $\begin{array}{c}\text { Conven* } \\
\text { tional } \\
\text { electricity }\end{array}$ & $\begin{array}{c}\text { Electricity } \\
\text { export }\end{array}$ & $\begin{array}{c}\text { Electricity } \\
\text { spot price }\end{array}$ & $\begin{array}{c}\text { Reduction } \\
\mathrm{CO}_{2-} \\
\text { emissions }\end{array}$ & $\begin{array}{c}\text { Reduction } \\
\text { of } \mathrm{CO}_{2^{*}} \\
\text { emissions }\end{array}$ & $\begin{array}{c}\text { of } \\
\text { domestic } \\
\text { RES-E }\end{array}$ \\
\hline A & TWh & TWh & TWh & TWh & cE/kWh & MT/year & MT/year & MT/year \\
\hline B & 0.2 & 4.2 & $38.9(-0.9)$ & 3.1 & 2.8 & 35.0 & 0.90 & 0.18 \\
\hline C & 0.3 & 5.3 & $33.6(-0.8)$ & -7.1 & 2.8 & 28.5 & 0.70 & 0.26 \\
\hline Total & 2.2 & 8.2 & $29.8(-1.0)$ & 4.0 & 2.8 & 23.8 & 0.80 & 1.76 \\
\hline
\end{tabular}

Table 2: The consequences for $\mathrm{CO}_{2}$-emissions of an increase in renewable power production. Still no TGCs or TEPs present. (Adapted from Morthorst (2003))

The total reduction of $\mathrm{CO}_{2}$-emissions amount to $2.4 \mathrm{MT}$ per year, which is shown in the second to last column in Table 2 . This is $10 \%$ more than what could have been achieved if the 
countries did not trade electricity with each other. The no trade reductions are found in the last column of Table 2 . The new equilibrium gives a problem to Country $\mathrm{C}$ since half of their potential domestic reduction of $\mathrm{CO}_{2}$-emissions has been transferred to the other two countries, both reducing their conventional electricity by far more than their deployment of RES-E. On the other hand it looks like Country $\mathrm{C}$ has some compensating gains from the electricity trade, since domestic aggregated production and hence exports has increased.

Figure 7 below shows that the spot market price declines due to the deployment of new RESE. The substitution of RES-E for conventional electricity depends on the steepness of the original supply curves. Since Country $\mathrm{C}$ has the steepest supply curve they will face the largest reduction of conventional electricity, but since the supply curves of the two other countries are very similar they will also carry some of the reduction. It is important to emphasise that the reduction in the three countries will be the same no matter how the deployment of 2.7 TWh of RES-E is distributed among the three countries.

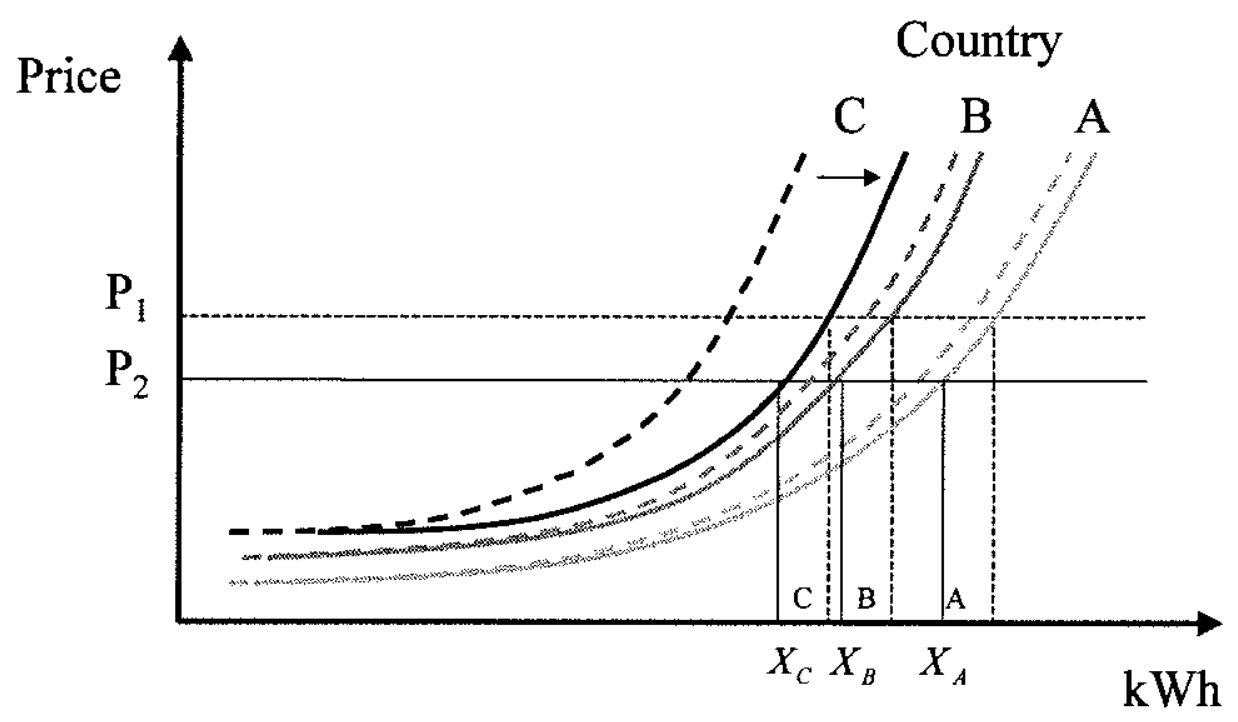

Figure 7. Spot market changes as result of an increase in RES-E in the three countries. (Source: Morthorst (2003))

The domestic benefit of deploying RES-E is thus restricted to the domestic reduction of conventional electricity. Given the data in the model and the amount of $2.7 \mathrm{TWh}$ of new RES-E, only a deployment of RES-E with 0.9 TWh, 0.7 TWh and 0.8 TWh in Country A, B and C respectively would lead to a full benefit of the deployment to all the countries involved.

\section{Exposition \# 8: Introducing internationally Tradable Green Certificates}

The international deployment of RES-E depends on the relative marginal cost of deploying RES-E. In equilibrium the deployment is such that the marginal cost of deploying is the same in the three countries. The implies that the ambitious target in Country $\mathrm{C}$ does not necessarily imply a corresponding ambitious deployment of RES-E, but even with less domestic deployment the citizens of Country $\mathrm{C}$ will still bear the full cost of the target through the excess cost related to the purchase price of TGCs.

In order to reduce the total cost of deploying RES-E in the three countries Morthorst (2001, 2003) introduces the opportunity to internationally trading the TGCs. The results are found in Table 3. 


\begin{tabular}{|c|c|c|c|c|c|c|c|}
\hline \multirow[b]{4}{*}{ Country } & \multicolumn{2}{|c|}{ Pre-TGC trade } & \multicolumn{5}{|c|}{ Introducing a common TGC-market } \\
\hline & \multirow{2}{*}{$\begin{array}{l}\text { Conven- } \\
\text { tional } \\
\text { electricity }\end{array}$} & \multirow{2}{*}{$\begin{array}{c}\text { Renewable } \\
\text { power pro- } \\
\text { duction }\end{array}$} & \multicolumn{2}{|c|}{ Renewable quota } & \multirow{2}{*}{$\begin{array}{l}\text { Actual in- } \\
\text { crease in } \\
\text { RES-E }\end{array}$} & \multirow{2}{*}{$\begin{array}{c}\text { TGC } \\
\text { import }\end{array}$} & \multirow{2}{*}{$\begin{array}{l}\text { Conven- } \\
\text { tional } \\
\text { electricity }\end{array}$} \\
\hline & & & Total & Increase & & & \\
\hline & TWh & TWh & TWh & TWh & TWh & $\mathrm{MT} / \mathrm{y}$ & TWh \\
\hline $\mathrm{A}$ & 39.8 & 4.0 & 4.2 & 0.2 & 4.9 & -0.7 & 38.9 \\
\hline $\mathrm{B}$ & 34.4 & 5.0 & 5.3 & 0.3 & 5.8 & -0.5 & 33.6 \\
\hline $\mathrm{C}$ & 30.8 & 6.0 & 8.2 & 2.2 & 7.0 & 1.2 & 29.8 \\
\hline Total & 105.0 & 15 & 17.7 & 2.7 & 2.7 & 2.4 & 102.3 \\
\hline
\end{tabular}

Table 3. Adding an international TGC-market separately on a liberalised power market.

(Source: Morthorst (2001))

The $\mathrm{CO}_{2}$ emissions are exactly the same as with the national TGC markets. The social gain is only the reduced costs on the deployment of RES-E. Table 3 indicates clearly, that Country C should not focus as much on domestic deployment of RES-E as the TGC quota indicates.

\section{Exposition \# 9: Facilitating deployment with both TEPs and TGCs}

In order to be able to closely manage the reduction of $\mathrm{CO}_{2}$-emissions it might be fruitful to the countries to use tradable emission permits (TEPs) along with the TGCs. The TEPs impose extra cost to the conventional producers thus putting an upward pressure on the electricity spot price facilitating entry of RES-E, by reducing the RES-E suppliers need for income from the sale of TGCs. The optimal mix of the two instruments will be analysed in Exhibitions 13 through 19 below.

By allowing TEPs to be traded internationally we improve the cost-efficiency of the emission reduction. The more power plants covered by the TEP trading area, the lower the total reduction cost. Ideally, all emitting activities should be covered by the TEP scheme, but we assume the scheme to be limited to the conventional power plants in the three countries.

To illustrate the impact of an international TEP market Morthorst (2003) presents a twoperiod analysis indicating the analysis of international coherence regarding the quotas for TGCs and TEPs.

Consider an initial situation where the aggregated quotas of TGCs and TEPs are 15 TWh and $89 \mathrm{MT} /$ year respectively. This is very similar to Table 1 except for some rounding of. Table 4 shows the initial equilibrium values with respect to production and trade.

\begin{tabular}{|l|c|c|c|c|c|c|c|}
\hline & \multicolumn{2}{|c|}{ Quotas } & \multicolumn{2}{c|}{ Production } & \multicolumn{2}{c|}{ Trade } & \multirow{2}{*}{ CO $_{2 \text {-emissions }}$} \\
\cline { 2 - 8 } & TGC & TEP & RES-E & Conventional & TGC & TEP & Mh \\
\cline { 2 - 8 } & MT/y & TWh & TWh & TWh & MT/y & MT/y \\
\hline Country A & 4.0 & 35 & 4.27 & 39.8 & 0.27 & -0.50 & 35.50 \\
\hline Country B & 5.0 & 29 & 5.05 & 34.4 & 0.05 & -0.09 & 29.09 \\
\hline Country C & 6.0 & 25 & 5.68 & 30.8 & -0.32 & 0.59 & 24.41 \\
\hline Total & 15.0 & 89 & 15.0 & 105.0 & 0.0 & 0.0 & 89.0 \\
\hline
\end{tabular}

Table 4. Period one. The interactions of an international TEP-market with an international TGC-market in a liberalised power market. (Source: Morthorst (2003))

Both Country A and B have reduced the emission quota compared to Table 1, whereas Country $\mathrm{C}$ has expanded the quota. The first result here is that the $6 \mathrm{TWh}$ of RES-E in Country C in Table 1 represents some excess deployment, since the optimal level is slightly lower. This is just a result of equalising marginal cost in of RES-E deployment in the three countries. Consequently, Country $\mathrm{C}$ must purchase TGCs from the two other countries to meet their own 
TGC quota. Country A and B deploy RES-E in excess of their TGC quota, because the have lower RES-E cost that Country C.

In order to track the interaction between the two instruments when international TGC or TEP trades are allowed, we reuse the TGC quotas from Table 2. Furthermore we impose an equal reduction of emissions by reducing the TEP quota by $2 \mathrm{MT} / \mathrm{year}$ in each country. Table 5 below summarises the results when the domestic quotas are set irrespective of the relative cost and emissions structure.

\begin{tabular}{|c|c|c|c|c|c|c|c|}
\hline & \multicolumn{2}{|c|}{ Quotas } & \multicolumn{2}{|c|}{ Production } & \multicolumn{2}{|c|}{ Trade } & \multirow[b]{2}{*}{$\mathrm{CO}_{2}$-emissions } \\
\hline & TGC & TEP & RES-E & Conventional & TGC & TEP & \\
\hline & TWh & MT/y & TWh & TWh & TWh & $\mathrm{MT} / \mathrm{y}$ & $\mathrm{MT} / \mathrm{y}$ \\
\hline Country A & 4.2 & 33 & 4.92 & 38.9 & 0.72 & 0.04 & 32.96 \\
\hline Country B & 5.3 & 27 & 5.77 & 33.6 & 0.47 & -0.55 & 27.55 \\
\hline Country C & 8.2 & 23 & 7.01 & 29.8 & -1.19 & 0.51 & 22.49 \\
\hline Total & 17.7 & 83 & 17.7 & 102.3 & 0.0 & 0.0 & 83.0 \\
\hline
\end{tabular}

Table 5. Period two. The consequences of emission reduction with international markets for TEPs and TGCs. (Adapted from Morthorst (2003))

Table 5 shows that the distribution of the deployment of RES-E is independent of the introduction of a TEP scheme. Again, Country A and B choose to deploy RES-E in excess of their TGC quota, and the RES-E production remains unaltered from Table 4. This is because the deployment of RES-E only relies on the relative RES-E competitiveness in the three countries. Country A is not an active trader on the TEP market. Country B has now become active compared to Table 4 . Country $\mathrm{C}$ has now excess production capacity and offers TEPs in the market. This excess production capacity helps the two other countries to meet their emission quota. Unfortunately, these positive externalities will give Country $\mathrm{C}$ the full benefits for its RES-E deployment.

Alternatively, international co-ordination of the emission quotas to incur emission trading might improve the overall efficiency of the quota system. In Table 6 the national emission quotas are further reduced by the emission value of the national TGC quotas.

\begin{tabular}{|l|c|c|c|c|c|c|c|}
\hline & \multicolumn{2}{|c|}{ Quotas } & \multicolumn{2}{c|}{ Production } & \multicolumn{2}{c|}{ Trade } & \multirow{2}{*}{ CO $_{2}$-emissions } \\
\cline { 2 - 7 } & TGC & TEP & RES-E & Conventional & TGC & TEP & TW/y \\
\cline { 2 - 7 } & TWh & MT/y & TWh & TWh & TWh & MT/y & MT/ \\
\hline Country A & 4.2 & 32.83 & 4.92 & 38.9 & 0.72 & 0.76 & 32.07 \\
\hline Country B & 5.3 & 26.75 & 5.77 & 33.6 & 0.47 & -0.27 & 27.02 \\
\hline Country C & 8.2 & 21.34 & 7.01 & 29.8 & -1.19 & -0.48 & 21.82 \\
\hline Total & 17.7 & 80.93 & 17.7 & 102.3 & 0.0 & 0.01 & 80.91 \\
\hline
\end{tabular}

Table 6. Period two. The consequences of a co-ordinated development of the quotas in the TEP-and the TGC-markets in all participating countries. (Source: Morthorst (2003))

Despite the pressure on conventional production, the RES-E production remains unchanged. This means that the RES-E is still not able to compete at market conditions, i.e. without the subsidy from the TGCs. The pressure has though a clearly visible effect on emission trading. Furthermore, Country $\mathrm{C}$ will benefit domestically, since their emissions have been reduced by $0.67 \mathrm{MT} /$ year. The price for this achievement might still be too high, since Country $\mathrm{C}$ have reduced their sales of TEPs by almost $1 \mathrm{MT} /$ year. This mismatch origins from the low emission coefficient in Country $\mathrm{C}$, which makes it harder to generate an incentive though TEPs to switch to plants or fueIs with less emission. 


\section{Using TGCs as a policy instrument}

It is obvious from the previous section that $\mathrm{CO}_{2}$ emission reduction can by obtained by a proper application of a TEP scheme. Hence, the real mission of the TGCs must be to induce deployment of RES-E. Fristrup (2003) presents some of the challenges related to applying TGC as an instrument in the energy policy portfolio. The analysis is conducted from the RESE point of view focusing on the TGC instrument as a tool to induce efficient deployment of RES-E.

\section{Exposition \# 10: Short run RES-E supply}

Consider now a competitive domestic market for RES-E, meaning that the RES-E suppliers are competing with each other but not necessarily directly with the conventional suppliers on the power market. Furthermore, it is assumed that the marginal supplier on the short run RESE market is able to dispatch electricity. The marginal supplier is thus a biomass plant or a small hydro power plant. The determination of the short run RES-E supply is depicted in Figure 8 . The power price and the RES-E price are determined by the general demand and supply conditions. A thorough analysis of the determination of the equilibrium is given in Jensen \& Skytte (2001, 2002, 2003b), and will be presented later.

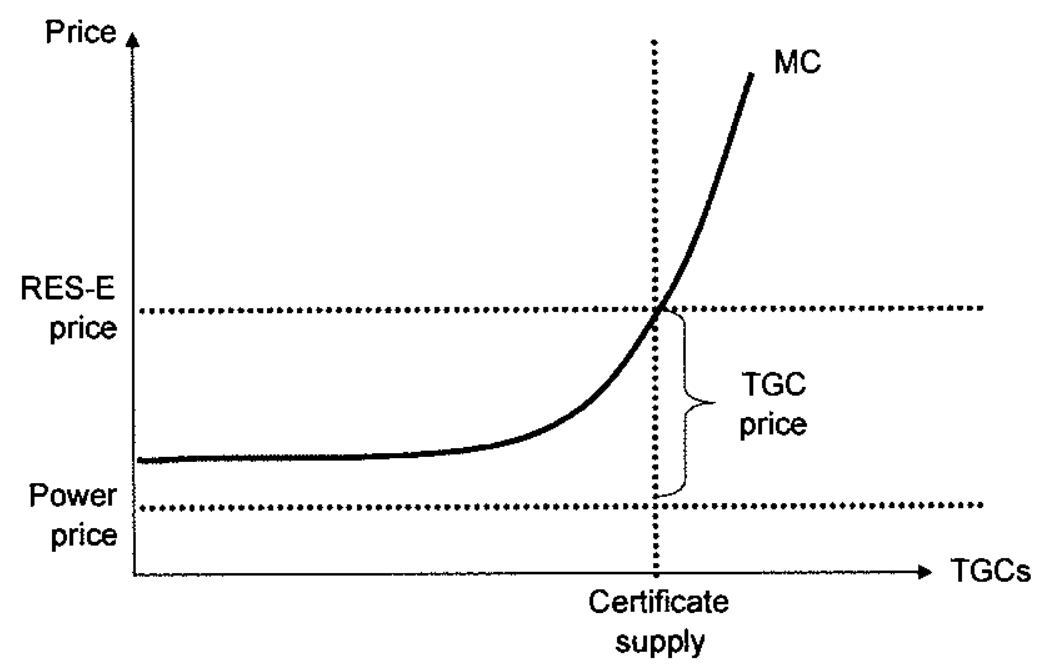

Figure 8. Supply based determination of the TGC price. The expected value of a TGC must be sufficient to cover the difference between marginal cost and the power price at the marginal RES-E producer. (Source: Fristrup (2003))

Assuming the short run supply to be a part of a long run equilibrium, the price of TGCs is assumed to be almost stable implying that the supply of certificates equals the supply of RES-E. The income to the RES-E suppliers consists of a contribution from selling RES-E at power market price together with an income from selling the TGC. The position of the power price line can be altered without changing the results, except that a higher power price would reduce the RES-E suppliers need from an income though the certificates.

Figure 8 reflects the assumption, that the marginal RES-E is a dispatcher equalising marginal cost with marginal revenue. Wind turbines are thus assumed to be the first to serve and they will gain profits to cover some or all of the capital cost. The marginal supplier has no profits, which call for a subsidy scheme for biomass because a supply equilibrium with no dispatchers has no focal point for the RES-E price and the TGC might be temporarily worthless due to the 
competition among wind turbines during that period. The again contradicts the assumptions made about the long run equilibrium.

It should also be noted that if the biomass subsidy scheme is a price subsidy, such a fixed price, then the biomass part of the supply curves moves down reducing the price on the TGCs. This price reduction implies furthermore a reduction of income to wind turbines and probably also a decline in deployment of wind turbines.

\section{Exposition \# 11: Long run RES-E supply}

To investigate the nature of induced deployment of RES-E it is necessary to focus on long run supply curves. The long run supply curves are based on total cost considerations, hence long run marginal cost (LRMC) should rightly be call expected long run average cost. To induce deployment of new RES-E it is required that the RES-E price, i.e. the sum of the power price and the certificate price, exceed the LRMC. Further do induce a pricing of the TGCs it might be necessary to force someone to purchase certificates, e.g. by assigning a mandatory purchase of TGCs to the consumers. Figure 9 below shows two instances of such a mandatory system, a low quota and a high quota.

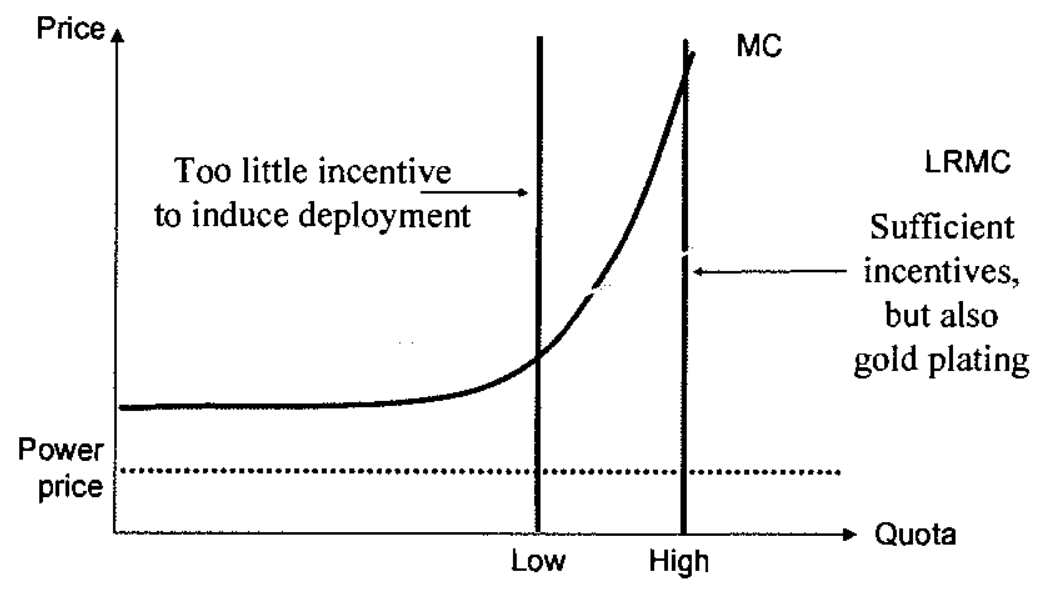

Figure 9. Inducing deployment. If the TGCs are priced sufficiently high and is able to cover average production cost on the marginal plant, it will also induce deployment of new plants.

(Source: Fristrup (2003))

At the low TGC quota the resulting RES-E price determined by the MC curve is positioned below the LRMC thus failing to cover the full cost of RES-E, hence deterring entry. Conversely, at the high TGC quota excess incentives are produced, transferring out of equilibrium excess income to incumbent RES-E suppliers. This gold plating could be transient phenomena, but if it persists then the scheme for deployment of RES-E will not be cost efficient. One way to reduce the risk of unintended gold plating is to lower the long run supply curves by giving investment subsidies as described in Exposition \# 2. But this is exactly what the TGC system is intended to supersede.

\section{Exposition \# 12: Fine tuning with TGCs}

It should be obvious from the previous exposition that failures regarding a co-ordination of short and long run incentives through a improper choice of the TGC quota might likely reduce the cost efficiency of the TGC system. The optimal quota management must solve this trade- 
off between short and long run incentives period after period. Figure 10 illustrates one possible development path for an optimal TGC quota.

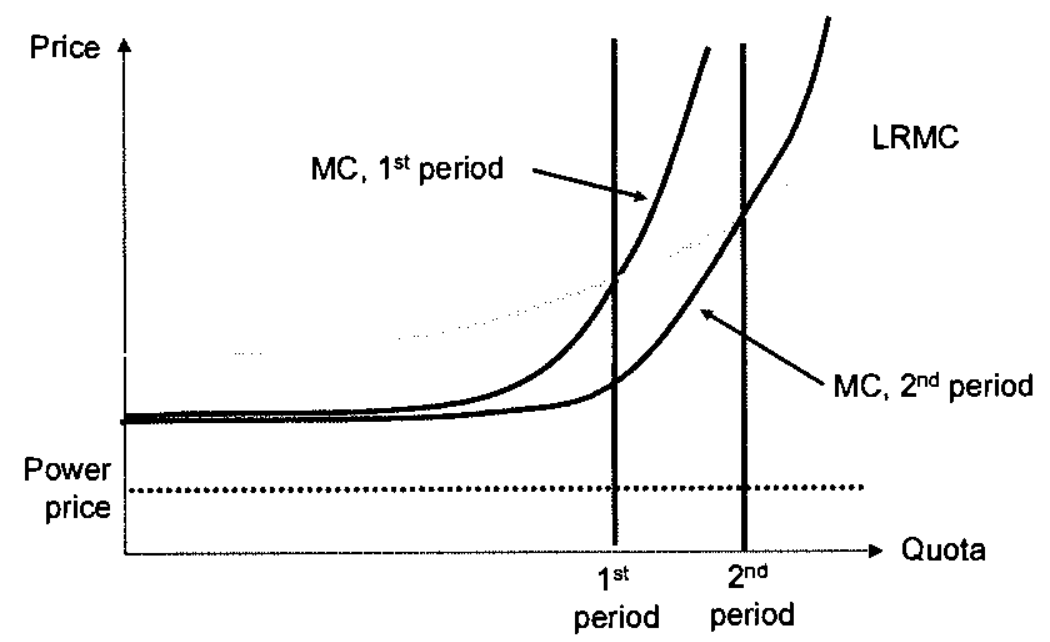

Figure 10. The TGC quota development path. The increase of the TGC quota must be set in close accordance with the RES-E cost structure to ensure efficiency.

(Source: Fristrup (2003))

The coexistence of RES-E and conventional electricity might complicate the attempt to managing the RES-E deployment through TGC quotas. One such complication is if the TGC scheme has an upper limit to the certificate price. It could be hard to avoid the limit to be binding, thus amputating the scheme. First, if RES-E deployment exceeds the growth in electricity consumption the power price is expected to fall due to excess supply. This will cause an increase in the certificate price. Second, if RES-E technology improvements are slow relative to the imposed deployment rate, the cost of deployment will grow rapidly, forcing the price on TGC to go up. Figure I1 indicates that a carbon tax on conventional electricity could help to reduce the skyrocketing of TGC prices.

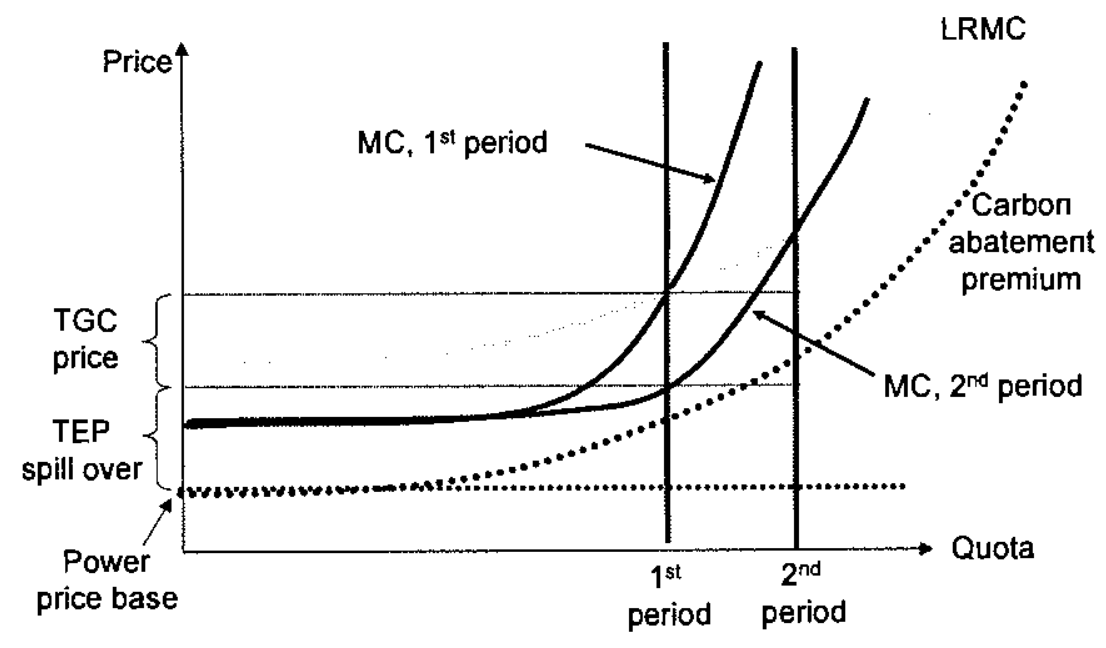

Figure 11. Fighting increasing TGC prices. By imposing a carbon tax on conventional electricity RES-E becomes more competitive and the TGC price will fall.

(Source: Fristrup (2003)) 


\section{Electricity as a composite commodity}

As indicated in the previous expositions, the markets for TGCs, TEPs and electricity are very closely related. The consumer price on electricity thus depends on the prices of both TGCs and TEPs. Jensen \& Skytte $(2001,2002,2003 \mathrm{~b})$ provides a simple framework to explore these relations. Their model contains two suppliers of conventional electricity, one RES-E supplier, and on consumer. Figure 12 below shows the relations between suppliers, consumers and markets.

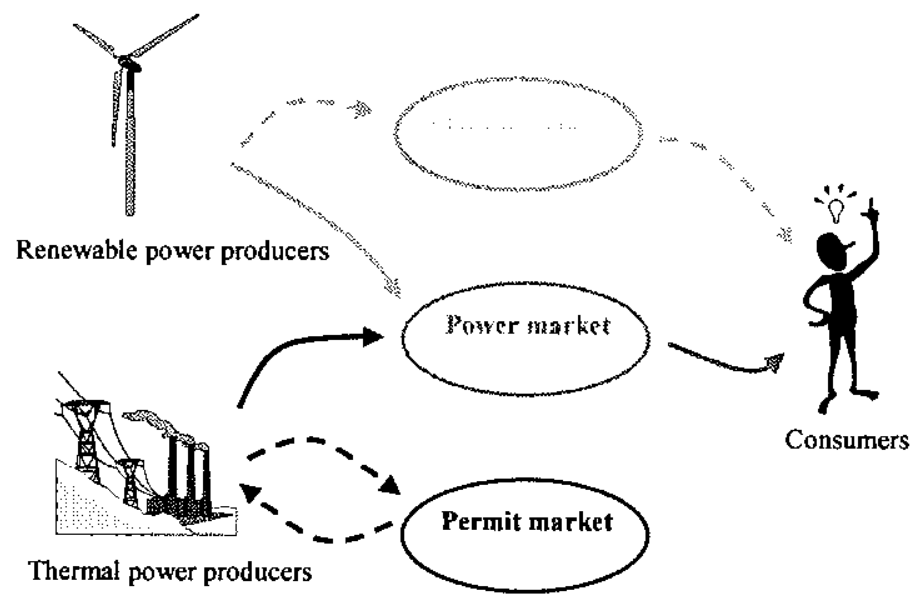

Figure 12. The interaction of the three markets. (Source: Jensen \& Skytte (2003b))

RES-E suppliers deliver their physical output of electricity to the power market and their financial output of TGCs to the certificate market. Conventional suppliers deliver their physical output of electricity to the power market. Furthermore, the trade at the emission permits market to adjust their TEP balances according to their production. Consumers face an electricity supply of mixed electrons, hence consumers can not screen the different types of electricity sources. Furthermore, consumers might be obliged to purchase TGCs to balance their consumption. All in all, electricity comes from two sources trading on three markets. The expositions to follow will present some of these complexities and the derived implications.

\section{Exposition \# 13: Engagement in three markets}

It the set-up in Jensen \& Skytte (2001) RES-E suppliers issue TGCs along with their production of electricity. Furthermore all RES-E suppliers are assumed to be dispatchers, i.e. able to control their output. All certificates will be traded during a production period. This is of course a simplification, but it corresponds to a stable equilibrium path. The suppliers of conventional are obliged to match their emissions by purchasing TEPs from a limited pool of permits. Furthermore, electricity consumers are obliged to purchase TGCs corresponding to a certain fraction of their electricity consumption. Further, to simplify calculations, all electricity suppliers are assumed to have quadratic cost functions.

The prices on the three markets will be interdependent since cost and production adds up to a point on the aggregated demand curve. Jensen \& Skytte (2001) aggregates three price relations between two markets at a time into common price regimes covering all three markets. 
The first price relation described is between the power market and the TEP market. If the introduction of an obligation on the conventional electricity suppliers to engage on the TEP market is binding it will induce an upward shift of the supply curve similar to the shift in Figure 5 above. Furthermore, the cost imposed by the TEPs reorder the position of the suppliers on the supply curve. The current model also implies the supply curve to become steeper.

The second price relation is between the power market and the TGC market. There is no voluntary purchase of TGC, hence if the TGCs are in excess supply their price will be zero. Due to the linearity in the second order conditions, the equilibrium TGC price can be expressed as a linear function of the electricity price. Furthermore, the certificate price is found to be negatively related to the electricity price, exactly as predicted in Exposition \# 13 above. The relation between the power market and the TGC market translates into Figure 13 below.

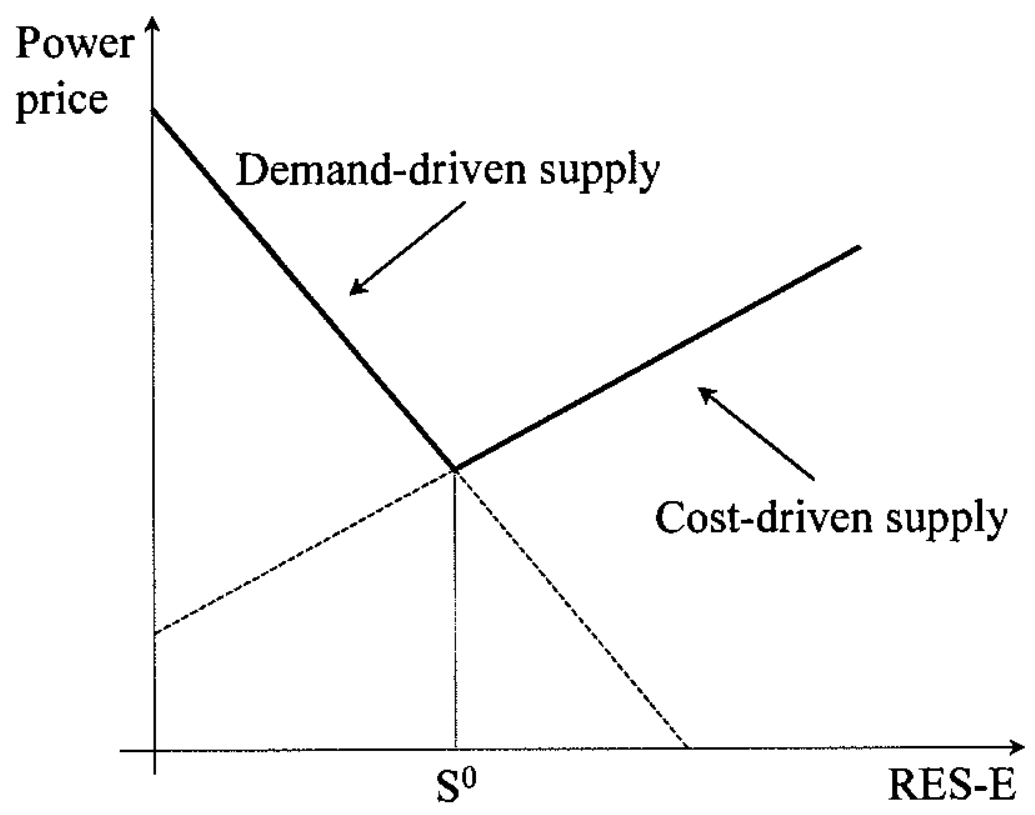

Figure 13. The relation between supply of RES-E and the power price. (Adapted from Jensen \& Skytte (2001)

As long as RES-E supply is limited, the obligation on consumers to partially match their consumption with TGCs becomes binding, resulting in a small aggregate power supply, leading to high prices (demand-driven supply). The RES-E suppliers are the able to exhibit market power on behalf of all suppliers, although the RES-E suppliers get the most, since the have extra income from selling their TGCs. Thus, the demand-driven supply curve is not identical to the demand curve for electricity, but a downward adjusted version of the curve with proper correction for the consumer cost of purchasing TGCs.

From point $S_{0}$ the supply of RES-E is no longer binding, TGCs will be worthless, and RES-E suppliers will supply at their marginal cost (cost-driven supply). This curve is the uncorrected RES-E supply curve as described in Exposition \# 13.

The third market relation is the relation between the TEP market and the TGC market. The prices on the two markets are negatively related since a high price on TEPs improves the competitiveness of the RES-E suppliers, thus leading to a lower certificate price. This negative relation, that the TGC quota and the TEP quota can be used as substitutes for each other. Furthermore, an extreme choice of one of the quotas will make the other quota redundant. 


\section{Exposition \# 14: Price regimes and instrument redundancy}

Jensen \& Skytte (2001) provides an illustration of the relation between the three prices, the price on electricity, $p_{e}$, the price on TGC, $p_{c}$, and the price on TEPs, $p_{p}$. Two instances of price relations resulting in four price regimes can prevail. They are all illustrated in Figure 14.
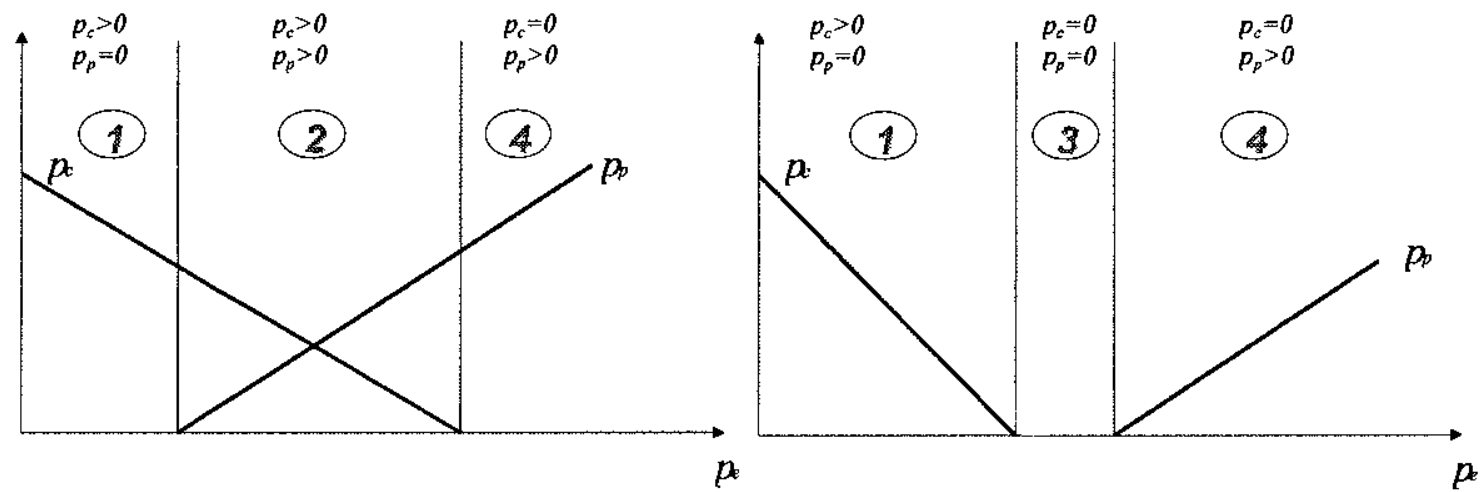

Figure 14. Four price regimes. The TEP quota becomes redundant at low electricity prices, whereas the TGC quota becomes redundant at high electricity prices.

(Adapted from Jensen \& Skytte (2001)

In both instances (left and right) the quota have be settled at a fixed level. The sloping lines respectively indicate the relations between the power price and the TGC and the TEP prices. At low electricity prices conventional suppliers are not very active, hence the emission quota will not be binding. As electricity prices go up, more and more conventional suppliers become active initiation a need for TEPs. Price regime number three with no trade of certificates or permits prevails when the electricity supply is high enough to induce RES-E supply, but not high enough to bring the conventional suppliers to the emission limit.

\section{Exposition \# 15: Welfare analysis}

In order to apply an optimal mix of the TGC and the TEP quota, it will be necessary to consult the welfare implication of the two instruments. Jensen \& Skytte (2003b) provides such an analysis. Their Figure 15 below depicts the pre regulation set-up, where suppliers of RES-E are all inactive due to their high cost. In order to emphasise the inelastic electricity markets the demand curve will be assumed to be vertical. This simplification will facilitate the evaluation of welfare gains and losses in the analysis.

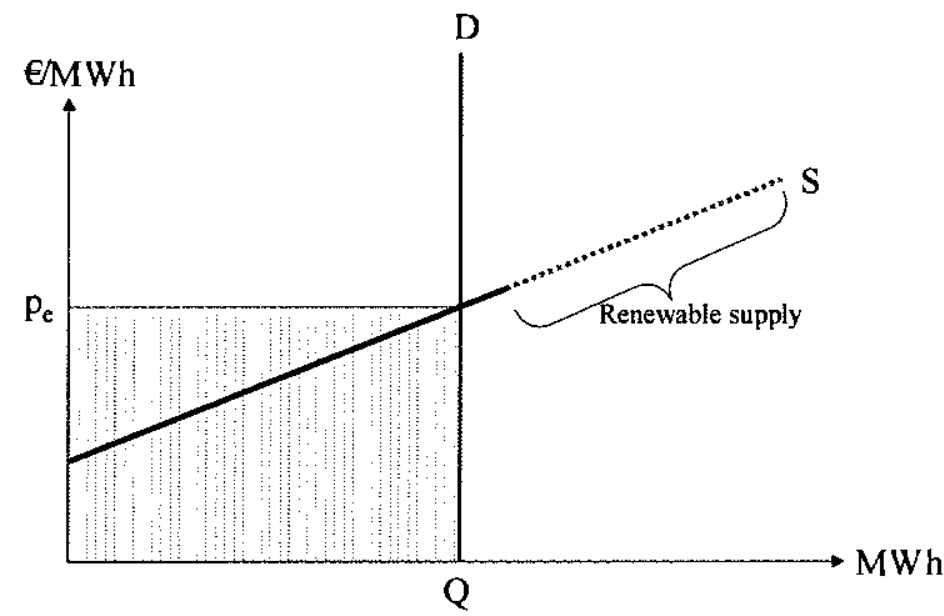

Figure 15. The electricity market prior to regulation. (Source: Jensen \& Skytte (2003b)) 
In the unregulated case the market equilibrium $\left(\mathrm{Q}, \mathrm{p}_{\mathrm{e}}\right)$ deters all the RES-E suppliers. In order to induce RES-E entry income must be transferred to the RES-E suppliers. Introducing a TGC quota brings RES-E suppliers in play corresponding to the size of the quota. The change in equilibrium is shown in Figure 16 below.

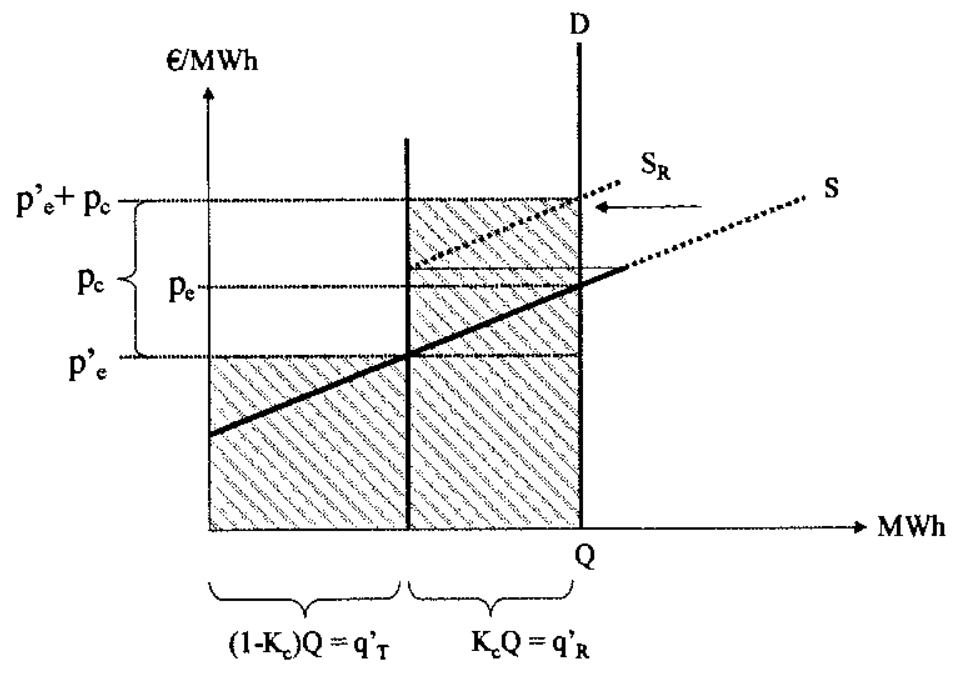

Figure 16. The electricity market when a TGC quota has been introduced.

(Source: Jensen \& Skytte (2003b))

$P_{c}$ is the equilibrium price on TGCs. $K_{c}$ is the fraction of electricity consumption that has to be matched by TGCs. The existence of the matching obligation moves RES-E in play, replacing high cost conventional suppliers. Since the income to RES-E suppliers is secured by the regulation it is fair to assume that the electricity market price will be determined by the marginal conventional supplier, thus leading to a fall in the electricity price. The welfare gains (saved cost) is the white box below the $\mathrm{p}_{\mathrm{e}}$ line and the welfare loss (the additional cost) is the shaded box above this line. At this general level it is impossible to determine whether the introduction of a TGC quota implies a net welfare loss.

To investigate the welfare implications of introducing an emission quota alone Figure 17 depicts the movement of the equilibrium. The RES-E incentive is now a higher electricity price through an increase induced by the cost of the TEPs. This type of regulation produces a net welfare loss.

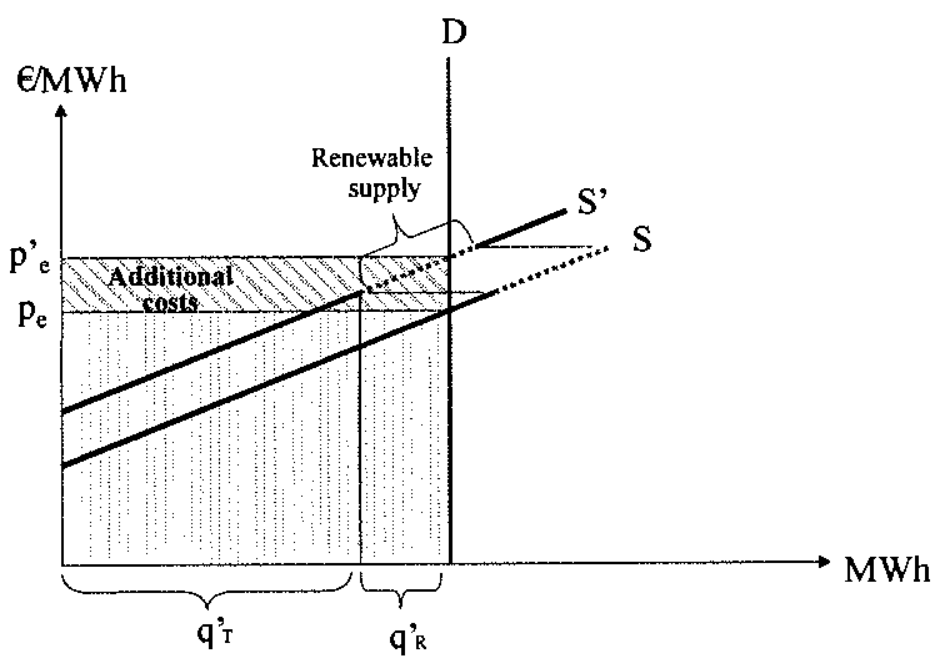

Figure 17. The electricity market with an emission quota. (Source: Jensen \& Skytte (2003b)) 


\section{Exposition \# 16: A renewable energy goal with two regulatory instruments}

In order to counteract some of the problems with the TGC schemes, the energy authorities might want to apply both a TGC and a TEP scheme to the power market in order to achieve a specific target on the RES-E deployment. Jensen \& Skytte (2003b) provides an analysis of the interdependence between the two schemes when they are aimed at RES-E deployment.

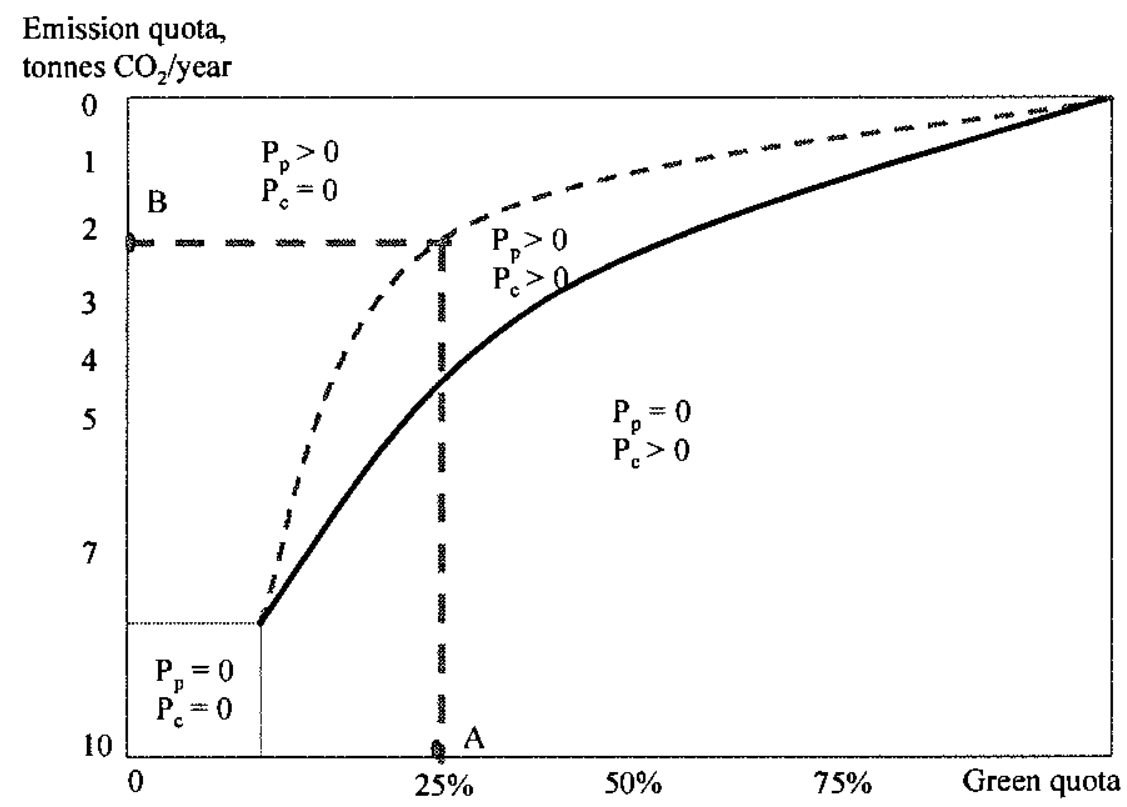

Figure 18. Achieving a $25 \%$ share of RES-E through a TGC scheme. (Source: Jensen \& Skytte (2003b)).

The vertical axis in Figure 18 represents the total quota for $\mathrm{CO}_{2}$ emissions from the electricity sector. A tightening of the restriction on emissions is thus a movement upward on this axis. The green quota on the horizontal axis is the share of RES-E in relation to total electricity consumption is represented at the horizontal axis. $P_{p}$ and $P_{c}$ represents the prices on TEPs and TGCs respectively. At high emission levels and low RES-E levels both TEPs and TGCs are worthless because of the lack of demand for them. As the energy policy becomes more restrictive they become more valuable.

A TEP system creates $\mathrm{CO}_{2}$ reductions but also some deployment of RES.E. The upper (dotted) curve in the figure represents the cross-effectiveness of the TEP system, i.e. the autonomous amount of RES-E resulting from imposing an emission quota. If an emission quota is to be combined with a deployment of RES-E exceeding the level given by the curve then it will be necessary to apply a TGC system also. Conversely, a TGC system induces supply of RES$\mathrm{E}$, but it will also imply some autonomous reduction of emissions. The relation is represented by the solid (lower) curve. If there is a need to reduce emissions further than the level given by the solid curve, a TEP scheme is needed. Only at points between the two curves both schemes will be needed. Outside this area at least one on the instruments will be obsolete.

The vertical dotted line in Figure 18 represent a $25 \%$ green quota. This goal can be reached in two ways using a single instrument at a time. A 2 tonne emission quota does the job, but it could of course also be achieved by using a TGC scheme aiming directly a $25 \%$. The latter approach will lead to an emission level as high as 4.5 tonne.

To find an optimal mix of the two schemes it is necessary to evaluate the result against an overall objective. In the analysis by Jensen \& Skytte (2003b) the overall objective is to mini- 
mise the consumer cost of electricity calculated as the average cost of electricity when both generation cost, cost of TEPs and cost of TGC are included.

Figure 19 below is an enhancement of Figure 18. Two new iso-price curves have been introduced. Depending on the cost curves in the model these iso-price curves can have different shapes despite the synergy between the two schemes.

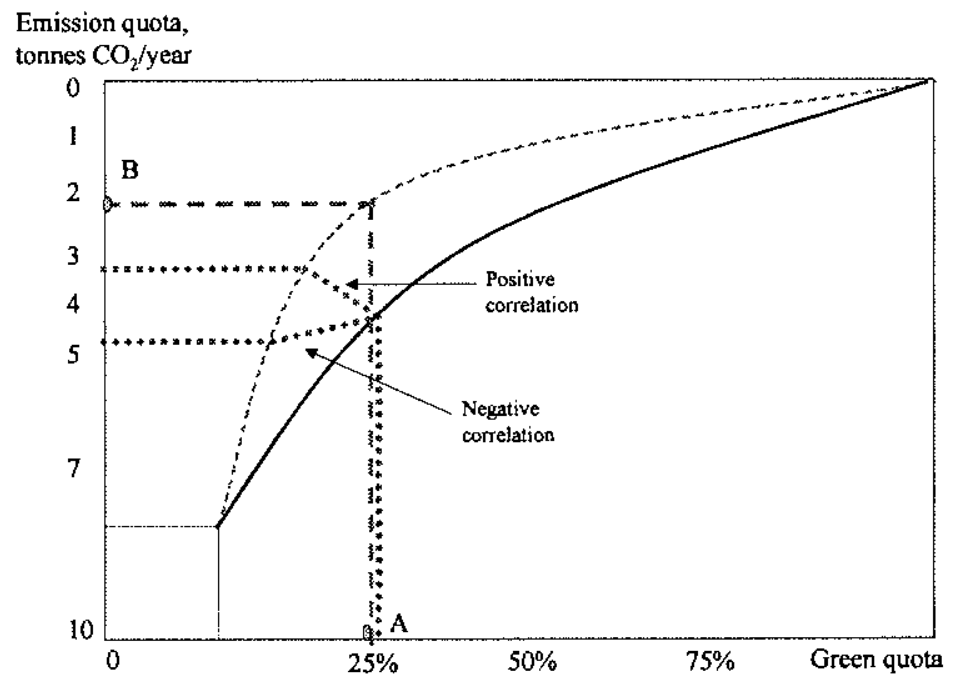

Figure 19. The introduction of consumer prices. (Source: Jensen \& Skytte (2003b)).

Two extreme iso-price curves are now introduced into the analysis. The consumer cost is increasing moving up or right from an iso-price curve. The upper dotted iso-price curve represents a scenario with a positive correlation between the consumer price and the green (TGC) quota, and the lower dotted iso-price curve represents a negative correlation. The negative correlation curve reflects the situation where the additional cost of using the TEP scheme (see Figure 17) exceeds the additional cost of using the TGC scheme (see Figure 16). Both dotted curves nominate a set of combinations of RES-E deployment and emission reduction resulting in the same consumer price as choosing a $25 \%$ RES-E deployment without any restrictions on the emissions.

Using a TEP scheme result in a consumer cost in excess of using the TGC scheme, due to the strong emission restriction needed to impose a $25 \%$ RES-E deployment through an indirect mechanism. The TGC scheme would be preferable to the TEP at all green quota levels.

\section{Exposition \# 17: An emission goal supported by two regulatory instruments}

Figure 20 below from Jensen $\&$ Skytte (2003b) depicts the situation where the energy policy goal is to reduce emissions alone. As discussed above the application of a TGC scheme will also imply a decline in emissions. A $35 \%$ green quota would reduce the emission to about 3 tonne. 


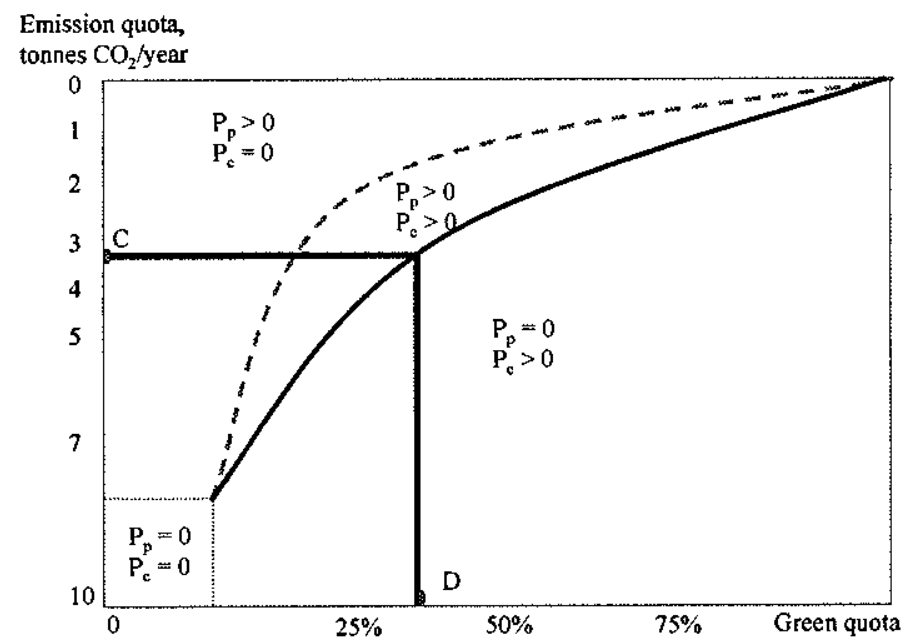

Figure 20. Achieving a 3 tonnes emission target through a TEP scheme.

(Adapted from Jensen \& Skytte (2003b)).

In order to derive an optimal mix of the two instruments, the consumer iso-price curves must be applied. This is done in Figure 21 below.

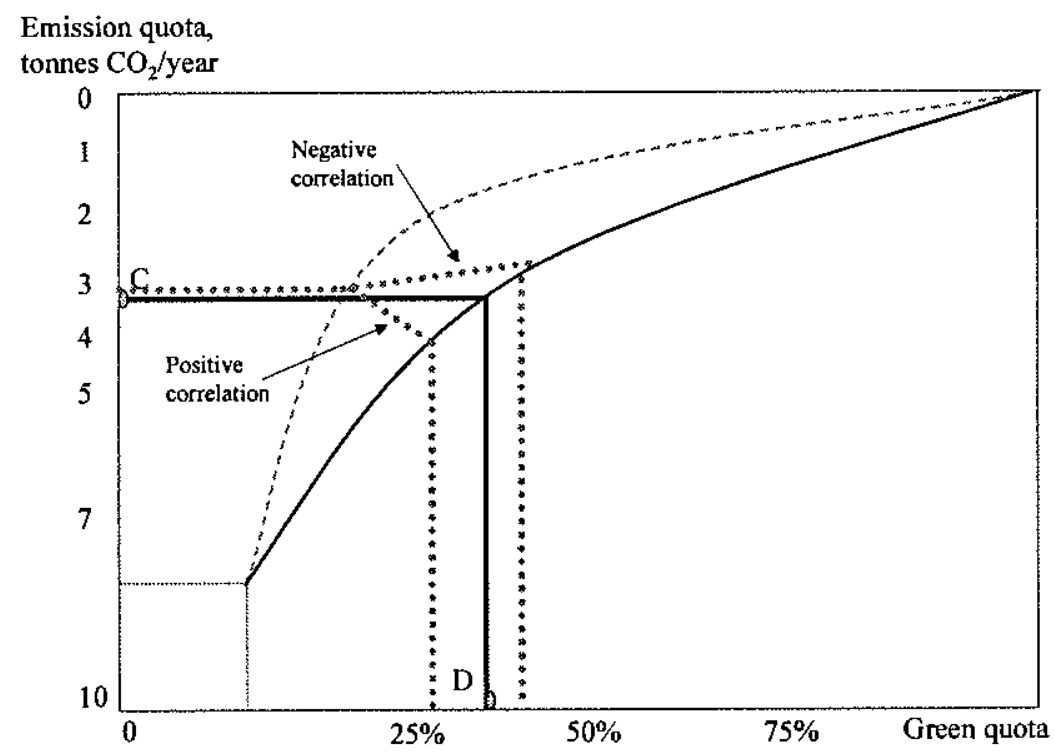

Figure 21. Using consumer prices to select an optimal policy mix.

(Source: Jensen \& Skytte (2003b))

The cost curves are the same as in the analysis on the RES-E target in the previous Exhibition, but now the shape of the curves are extremely important. Achieving a 3 tonne emission goal through a TEP scheme will lead to a low (about 20\%) share of RES-E. In the positive correlation scenario, all RES-E shares above the $20 \%$ level will impose extra cost on the consumers. Thus the TEP scheme is preferable to the TGC scheme or a mix of the two schemes in case of positive correlation. In case of negative correlation, the TGC is preferable to the TEP scheme, and mixes of the two are potentially even better, since it is possible to reduce consumer cost by marginal deployment of RES-E.

\section{Exposition \# 18: Two goals and two instruments}

The previous expositions concluded that a mix of the two instruments, TEPs and TGCs, was never an advantage if only one of the goals, emission reduction or RES-E share, were to be 
met. Furthermore, we saw that the application of one of the instruments in order to pursue one of the goals often lead to an improvement on the non-prioritised goal. Jensen \& Skytte (2003b) shows that in order to gain from a simultaneous use of both instruments, it takes not only a policy which focuses on both goals, it must also be so that this policy is less ambitious than what could have been achieved by using one instruments alone. Figure 22 below shows the attempt to meet a 3 tonnes emission target and a 25\% RES-E share target with one instrument alone.

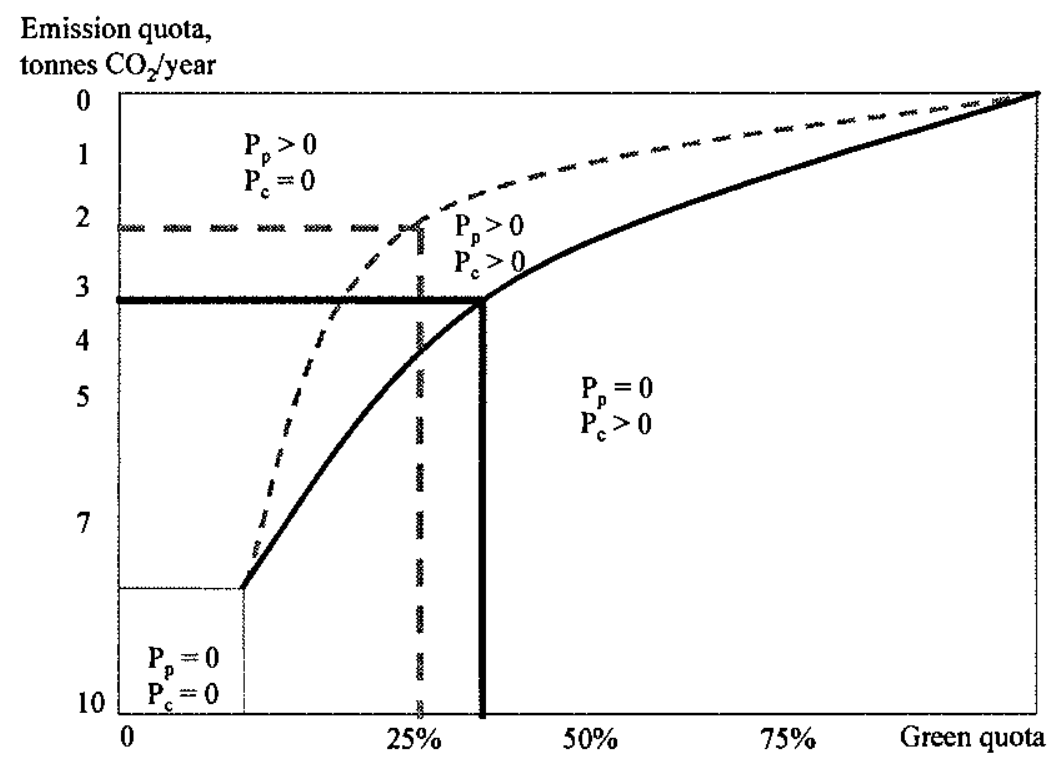

Figure 22. Achieving a 3 tonnes emission target and a 25\% RES-E share target with one instrument alone. (Source: Jensen \& Skytte (2003b))

Figure 22 summarises the benefits and problems origination from use one instrument only. The use of an instrument has a positive effect on the unprioritised goal, but this effect might be of an unwanted size. A proper combination of the two instruments facilitates an accurate energy policy on both goals. Figure 23 below shows such an analysis.

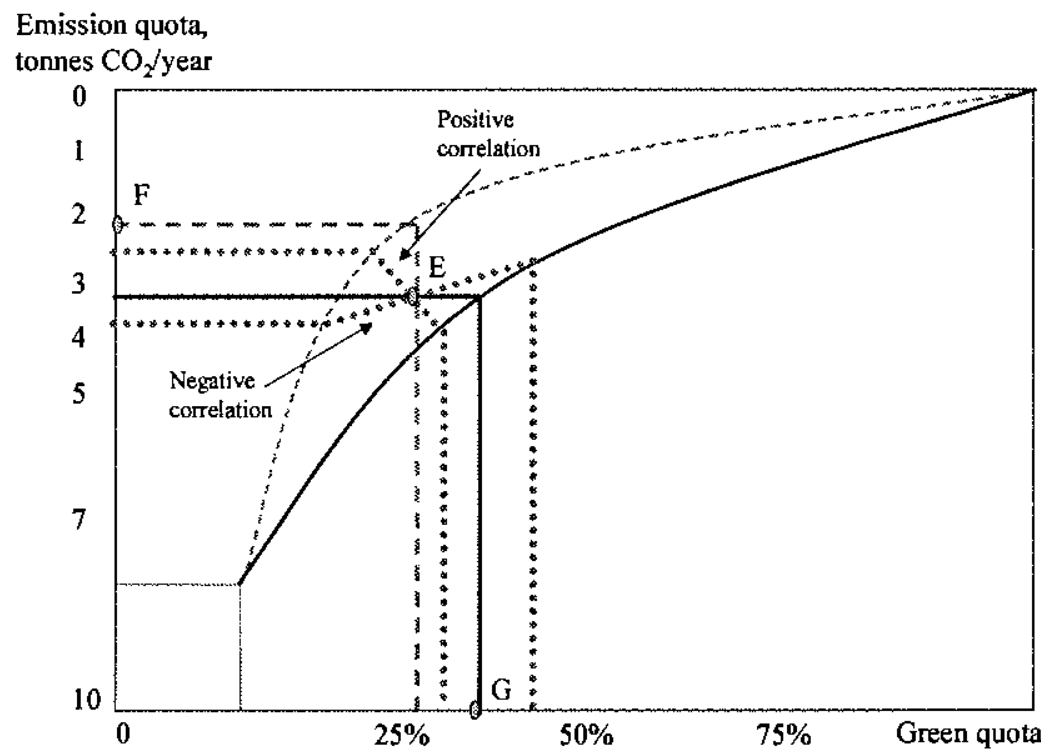

Figure 23. Consumer price analysis of achieving a 3 tonnes emission target and a $25 \%$ RES-E share target. (Source: Jensen \& Skytte (2003b)) 
Point $\mathrm{E}$ in the figure indicates the politically chosen combination of the two targets. Two isoprice curves, one with positive and one with negative correlation, have been selected to pass through point $E$ to be able to detect whether point $E$ is dominated, either by stronger targets at the same cost, or similar targets at lower cost. In the positive correlation scenario any other strategy with the same consumer cost would lead to a reduction of one of the targets. Thus using the combination of the two instruments to reach point $E$ is cost efficient in the positive correlation scenario. Again, the negative correlation scenario leads to other results. Similar to Figure 21 both targets can be improved at no extra cost to the consumers. This is done by using a TGC system alone to reach the RES-E share at the iso-price curve right of point G.

\section{Exposition \# 19: Alternative overall objectives}

It is obvious that deployment of RES-E results in abandoning some conventional electricity generation capacity. This abandoning is a cost to the owners of the capacity. To reduce the welfare loss through a too rapid abandoning of generation capacity, the emission reduction should be carefully chosen, whether it is directly managed through a TEP scheme or indirectly through the TGC scheme. This calls for policy makers to apply both instruments in order better to be able to control the pace of the transformation from conventional electricity to RES-E. 


\section{The international aspect of TGCs}

In order to improve the economic efficiency of both TEPs and TGCs trade on international markets would be preferable. Nielsen \& Jeppesen (2003) discuss the problems relating to migrate from national TGC systems to an internal market for TGC in the European Union. The ideal TGC system must contain some basic elements to ensure local cost efficiency. These elements are hopefully of such a nature that they can be mutated to comply with other national energy policies. The next expositions will determine how related these mutated species of TGC systems should be to facilitate a common TGC system.

\section{Exposition \# 20: The RECS certificate system}

Further to production and consumption of TGCs, a TGC system should also contain a certification authority and a reliable accounting system. A major problem is that RES-E is indistinguishable from all other energy sources at the point of consumption. An appropriate certification system helps to overcome this problem. At European level the RECS Group, consisting of mainly governmental authorities, energy agencies and energy companies from Netherlands, Denmark, England, Belgium, Germany, Italy, Sweden, Greece, France and Austria, have offered to be responsible for the facilitation of issuing, trading and redemption of TGCs. The main aim of the RECS Group is to stimulate (internationally harmonised) national markets for renewable energy certificates.

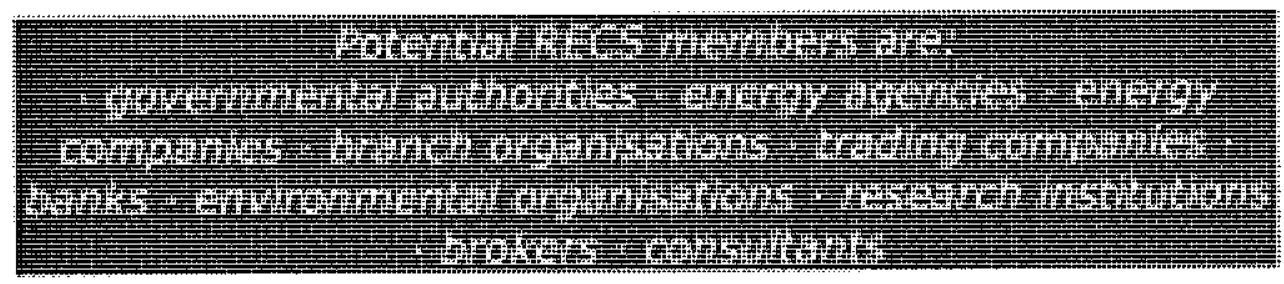

Figure 24. Facts about the RECS Group. (Source: www.recs.org)

The RECS, Renewable Energy Certificate System, is supervised by the RECS Group members, appointing a number of Issuing Bodies. The issuing bodies are each responsible for issuing, transferring ownership of and redeeming RECS certificates within their distinct geographical domains. Furthermore they must maintain a central registration database with details of all RECS certificates issued including their current ownership status. Figure 25 below shows the life span of the RECS certificate. The evidence of the generation of RES-E will be provided from the electricity distributor. Once this information is approved, the issuing body keeps track on the status of the issued certificates.

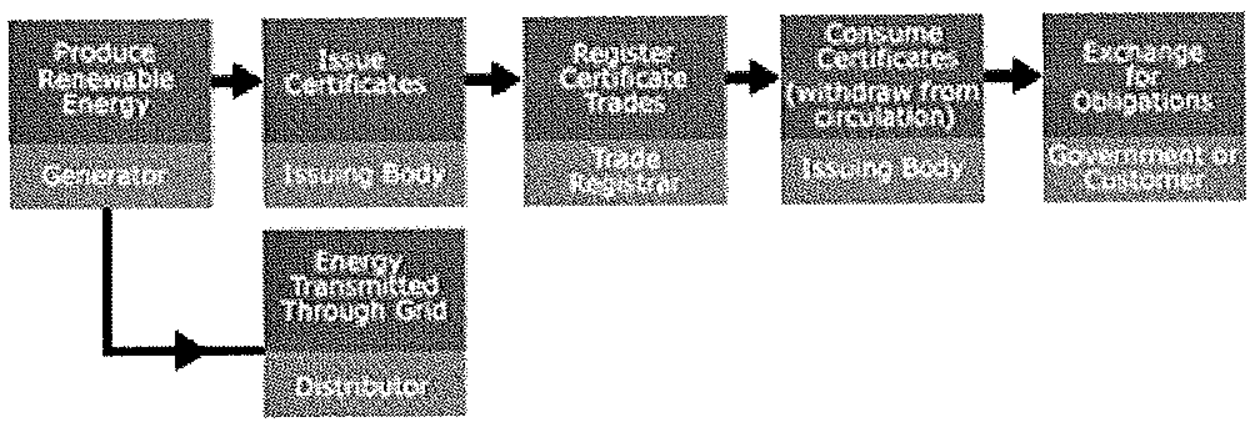

Figure 25. The life span of a RECS certificate. (Source: www.recs.org) 
A RECS certificate corresponds to the production of one megawatt hour (1 MWh) of RES-E. In order to link the benefit of RES-E over conventional electricity the certificate also states if the RES-E producer has received public support. Furthermore, the lifetime of the certificates will not be limited. Had this not be the case, the market for certificates would be fragmented into small markets for each vintage of certificates.

\section{Exposition \# 21: Technologies eligible for certificates}

There exists a wide spectrum of generation technologies not emitting green house gasses. The RECS Group has decided that nuclear power will not be eligible for RECS certificates, since it is not renewable. The definition of renewable energy sources applied in the European Union comprises wind, solar, geothermal, wave, tidal, hydropower, biomass, landfill gas, sewage treatment plant gas and biogases, European Commission (2001).

The European member states introducing TGC systems have individually chosen to exclude some of the technologies from the list above. Several countries have excluded hydropower with a generation capacity above $10 \mathrm{MW}$. Large-scale hydropower plants can not be placed anywhere. There exists a need for a large inflow of water (mountains) and a willingness to flood valleys to produce a reservoir. Furthermore, some of the member states have already a large supply of large-scale hydropower, potentially making them large suppliers of TGCs on an international market. Conversely, very small electricity plants of any type, and technologies yet to be matured, such as photovoltaic generation, would almost inevitably need subsidies, which would blur the purpose of the TGC. Table 7 below lists the technologies eligible for TGCs in six member states.

\begin{tabular}{|l|l|l|l|}
\hline Country & Technologies excluded & $\begin{array}{l}\text { Production eligible } \\
\text { for certification }\end{array}$ & Existing plants included \\
\hline Flanders region & $\begin{array}{l}\text { Incineration of non- } \\
\text { organic waste }\end{array}$ & $\begin{array}{l}\text { Electricity } \\
\text { Heat } \\
\text { Gas }\end{array}$ & Yes \\
\hline Denmark & $\begin{array}{l}\text { Waste } \\
\text { Hydropower }>10 \mathrm{MW}\end{array}$ & Electricity & After phase of transition \\
\hline Germany & Non-organic waste & Electricity & $?$ \\
\hline Italy & Pumping hydro & Electricity & No \\
\hline Netherlands & $\begin{array}{l}\text { Non-organic waste } \\
\text { Industrial heat pumps }\end{array}$ & $\begin{array}{l}\text { Electricity } \\
\text { Heat } \\
\text { Gas }\end{array}$ & Yes \\
\hline UK & Hydropower $>10 \mathrm{MW}$ & Electricity & $?$ \\
\hline
\end{tabular}

Table 7. The scope of certification. (Adapted from Nielsen \& Jeppesen (2003))

Two major obstacles regarding homogeneity of the certificates exist. First, some countries have expanded the scope of certification beyond the generation of electricity. This expansion is correct from an environmental point of view, but it goes beyond the content of European Commission (2001). The other problem is that some countries have excluded large-scale hydropower. Time will show whether these exclusions can be considered as barriers to trade. 


\section{Exposition \# 22: Mechanisms for market stabilisation}

The market institutions established to facilitate the trade of TGCs in the individual member states might also pose a problem to the creation of an internal TGC market. Table 8 below summarises some of the institutional arrangements of the TGC markets in six member states.

\begin{tabular}{|c|c|c|c|c|c|c|}
\hline Country & $\begin{array}{l}\text { Market } \\
\text { stabiliser }\end{array}$ & $\begin{array}{l}\text { Banking/ } \\
\text { Borrowing }\end{array}$ & $\begin{array}{l}\text { Maximum } \\
\text { price/kWh }\end{array}$ & $\begin{array}{l}\text { Minimum } \\
\text { price/kWh }\end{array}$ & $\begin{array}{l}\text { Penalty for } \\
\text { non-compliance }\end{array}$ & $\begin{array}{l}\text { Period of } \\
\text { validity }\end{array}$ \\
\hline Flanders & No & $\begin{array}{l}\text { Banking: Yes } \\
\text { Borrowing:? }\end{array}$ & $\begin{array}{l}\text { 2001: } 2 \mathrm{BF} \\
2002: 3 \mathrm{BF} \\
2003: 4 \mathrm{BF} \\
2004: 5 \mathrm{BF}\end{array}$ & No & $\begin{array}{l}\text { Maximum price } \\
\text { to regulator }\end{array}$ & 2 years \\
\hline Denmark & $\begin{array}{l}\text { Renewable } \\
\text { Energy } \\
\text { Fund }\end{array}$ & $\begin{array}{l}\text { Banking: Yes } \\
\text { Borrowing: } \\
\text { With deposit } \\
\text { sum }\end{array}$ & $(0.27 \mathrm{DKK})$ & $0.10 \mathrm{DKK}$ & $\begin{array}{l}\text { Maximum price } \\
\text { to Renewable } \\
\text { Energy Fund }\end{array}$ & Unlimited \\
\hline Germany & No & $?$ & $?$ & No & $?$ & $?$ \\
\hline Italy & $\begin{array}{l}\text { Issuing } \\
\text { Body } \\
\text { (GRTN) }\end{array}$ & $\begin{array}{l}\text { Banking: No } \\
\text { Borrowing: } \\
\text { Against a } \\
\text { penalty price }\end{array}$ & $\begin{array}{l}\text { In principle } \\
\text { none }\end{array}$ & No & $\begin{array}{l}\text { Access of sup- } \\
\text { ply to the grid } \\
\text { denied }\end{array}$ & 1 year \\
\hline Netherlands & No & $\begin{array}{l}\text { Banking: } \\
\text { Probably yes } \\
\text { Borrowing:? }\end{array}$ & Not relevant & No & Not relevant & Unlimited? \\
\hline UK & No & $?$ & $\begin{array}{l}\text { Probably } \\
\text { around } 2 p \text { in } \\
\text { excess of the } \\
\text { market value } \\
\text { of electricity }\end{array}$ & No & $?$ & $?$ \\
\hline
\end{tabular}

Table 8. Market conditions and institutional arrangements of the national TGC systems.

(Source: Nielsen \& Jeppesen (2003))

In order to avoid that the TGC price increase to very high levels due to mismatches between the supply of TGCs and the obligations to purchase TGCs, Denmark and Italy have introduced "emergency exits" rather than proper price caps. In Denmark, consumers short of TGCs can be relieved from their unsettled obligations by paying a fine to a central RES-E fund. The level of this fine will be an effective price cap on the TGC market, since no rational consumer would purchase TGCs at a higher price. The Italian issuing body, GRTN, is allowed to conduct some "open market operations" through issuing "virtual certificates", thus reducing the TGC price, cf. Lorenzoni (2003).

Other important differences between the six systems above are the borrowing and banking opportunities and also the life span of the certificates. Since the life span of an Italian TGC is only one year, banking is by definition impossible. Flanders (the Flemish region in Belgium) as well as Denmark and probably also The Netherlands allow for banking of TGCs, although the two-year life span of the Flanders certificates does not fully comply with idea of banking. 


\section{Exposition \# 23: Mechanisms for initiating demand}

The demand for TGC must be initiated through political decisions about the role of the RES-E in the countries. Demand can be voluntary, such as in The Netherlands, where the Dutch association of energy distributing companies voluntarily agreed to meet a RES-E target through issuing TGCs. In order to stimulate the RES-E supply beyond that of a voluntary agreement, a commitment must be forced upon one of the downstream components, such as suppliers of conventional electricity, distributors or consumers. Table 9 below summarises some of the information regarding the demand mechanisms and the legislation.

\begin{tabular}{|l|l|l|l|}
\hline Country & Legal basis & Intended start date & Mechanisms to initiate demand \\
\hline Flanders & planned & January 2001 & -supplier obligation \\
\hline Denmark & yes & January 2002 & -end-user obligation \\
\hline Germany & no & $?$ & -grid company obligation \\
\hline Italy & yes & January 2001 & -producer obligation \\
\hline Netherlands & no & January 2001 & -voluntary purchase of TGCs \\
\hline United Kingdom & planned & $?$ & $\begin{array}{l}\text {-supplier obligation } \\
\text {-tax-exemptions }\end{array}$ \\
\hline
\end{tabular}

Table 9. Legal status and mechanisms to initiate demand. (Source: Nielsen \& Jeppesen (2003))

At the moment the German obligation is placed with the grid companies. In the future it is possible that the mechanisms to initiate demand will be a supplier obligation combined with eco-tax exemptions. The Danish scheme has been delayed awaiting a common European Union scheme. Meanwhile the RES-E suppliers who were supposed to obtain TGCs receive in stead a 1.33 cEURO payment on top of the electricity market price.

There exist five different mechanisms for initiating demand. This is a mess but should not be a problem to the internal market for TGCs. The only problem is that countries with no legal basis for the TGCs such as Germany and The Netherlands have no means to counteract situations where a domestic excess production of RES-E results in flooding the internal market with TGCs. This is not a problem to the market, but could be politically unacceptable, due to the distorted burden sharing. On the other hand, countries with the best RES-E sites should also be the dominating producers of RES-E.

\section{Exposition \# 24: Coexisting regulatory schemes directed at renewable energy}

Different national arrangements of price supports, fixed feed in tariffs and investment subsidies reduces the efficiency of an internal RES-E market. The supply curve of the individual RES-E supplier will rely on non-market income rather than market income and technology. The RECS certificate can be earmarked to indicate whether investment, production or both are subsidised. Unfortunately, this subsidy information will divide the TGC market into smaller segments with possibly more market power and hence less efficiency.

Table 10 below lists some of these disharmonious arrangements. To overcome the problems generated by the differences in governmental support schemes a pan national co-ordination will be necessary. 


\begin{tabular}{|l|c|c|c|}
\hline Country & $\begin{array}{l}\text { Price support } \\
\text { per unit of } \\
\text { RES energy } \\
\text { generated }\end{array}$ & Investment aid & End-use stimulation \\
\hline Flanders & $\mathrm{x}$ & $\mathrm{x}$ & $\mathrm{x}$ \\
\hline Denmark & $\mathrm{x}$ & $\mathrm{x}$ & \\
\hline Italy & & $\mathrm{x}$ & $\mathrm{x}$ \\
\hline Germany & $\mathrm{x}$ & & $\mathrm{x}$ \\
\hline Netherlands & & $\mathrm{x}$ & \\
\hline UK & & $\mathrm{x}$ & \\
\hline
\end{tabular}

Table 10. Co-existing national renewable energy regulation.

(Source: Nielsen \& Jeppesen (2003))

The transition to a common set of rules can not wait, since national uncertainties about future rules might discourage investments. To overcome this uncertainty countries might be tempted to guarantee long-term arrangements. The Danish fixed feed-in tariffs will be used for the existing RES-E plants in a very long transition period. The transition scheme would imply the expected number of TGCs issued to be only about half of the RES-E production in 2005 rising almost linearly to a full concordance in 2012.

\section{Exposition \# 25: A common European market for TGCs}

Nielsen \& Jeppesen (2003) claims that a European market for TGCs can be established in two ways. First, the ideal system with common rules and only few trade restrictions demand action now, prior to a widespread initiation of national uncoordinated TGC schemes. Second, if national schemes have been introduced, the European Union must work toward a harmonisation of the domestic markets.

The initiation of demand through imposing a minimum quota on consumers, producers or distributor may be interpreted as state aid according to EU law. Conversely, the Polluter Pays Principle adopted by EU would probably recognise the TGC scheme as a method to internalise the environmental cost of conventional electricity supply. Even with the legal problems solved the problems described in the previous four expositions still apply. 


\section{Financial risk in the TGC market}

Owners of wind turbines face an uncertainty regarding the meteorological condition for their the full load hours of electricity generation. Furthermore, the pricing of the TGC add further uncertainty to the income of a wind turbine owner. With national TGC schemes and a compulsory demand for TGCs, as the proposed Danish system, variation in wind leads to countervariations in the TGC price, since a low production of RES-E leads to an excess demand for TGCs. This is illustrated by the example in Table 13 below.

\begin{tabular}{|c|c|c|c|}
\hline Euro/MWh & Normal year & $\begin{array}{c}\text { Windy year } \\
\text { (large RES-E supply) }\end{array}$ & $\begin{array}{c}\text { Calm year } \\
\text { (little RES-E supply) }\end{array}$ \\
\hline $\begin{array}{l}\text { Certificate price } \\
\text { Power price }\end{array}$ & $\begin{array}{l}15 \in / \mathrm{MWh} \\
15 \in / \mathrm{MWh}\end{array}$ & $\begin{array}{l}10 \in / \mathrm{MWh} \\
15 \in / \mathrm{MWh}\end{array}$ & $\begin{array}{l}20 \in / M W h \\
15 \in / M W h\end{array}$ \\
\hline Total price & $30 \in / \mathrm{MWh}$ & $25 € / M W h$ & $35 € / M W h$ \\
\hline $\begin{array}{l}\text { Wind production } \\
\text { Total revenue }\end{array}$ & $\begin{array}{l}10 \mathrm{GWh} \\
300 \mathrm{k} €\end{array}$ & $\begin{array}{l}12 \mathrm{GWh} \\
300 \mathrm{k} €\end{array}$ & $\begin{array}{l}8,6 \mathrm{GWh} \\
300 \mathrm{k} €\end{array}$ \\
\hline
\end{tabular}

Table 13. Fluctuations in wind might leave the income to the owners of wind turbines unchanged.

In the table above a large RES-E supply is not enough to alter the market price for power, but the TGC price is expected to go down, reducing the total income from each $\mathrm{kWh}$ produce. But since the turbine owner faces more kilo-Watt hours than in a normal year, total income is the same. Likewise, calm years lead to high TGC prices, but since volume is lower, the total income is remains unaltered.

Danish wind turbine owners operate in a hydro based market, the Nordpool area, covering also Norway, Sweden and Finland. Fluctuation in precipitation has a large impact on the power market price. Table 14 gives an example on the impact on wind turbine revenues in a hydro based power market.

\begin{tabular}{|c|c|c|c|}
\hline Euro/MWh & Normal year & $\begin{array}{c}\text { Wet year } \\
\text { (large power supply) }\end{array}$ & $\begin{array}{c}\text { Dry year } \\
\text { (little power supply) }\end{array}$ \\
\hline Certificate price & $15 € / M W h$ & $20 \in / \mathrm{MWh}$ & $10 \in / \mathrm{MWh}$ \\
\hline Power price & $15 € / \mathrm{MWh}$ & $10 € / \mathrm{MWh}$ & $20 € / M W h$ \\
\hline Total price & $30 € / \mathrm{MWh}$ & $30 € / \mathrm{MWh}$ & $30 € / M W h$ \\
\hline $\begin{array}{l}\text { Wind production } \\
\text { Total revenue }\end{array}$ & $\begin{array}{l}10 \mathrm{GWh} \\
300 \mathrm{k} €\end{array}$ & $\begin{array}{l}10 \mathrm{GWh} \\
300 \mathrm{k} €\end{array}$ & $\begin{array}{l}10 \mathrm{GWh} \\
300 \mathrm{k} €\end{array}$ \\
\hline
\end{tabular}

Table 14. Fluctuations in precipitation might also leave the income to the owners of wind turbines unchanged.

In a set-up with compulsory TGC demand and both biomass and wind turbines the short run supply of RES-E is independent of the power market price, cf. Figure 8. Even without the biomass the lower power price would lead to an increased demand for power, leading to an increased demand for TGCs.

Lemming (2003) provides a formal analysis the financial risks related to such fluctuations in the TGC price. 


\section{Exposition \# 26: Price setting}

Lemming (2003) evaluates the proposed Danish TGC system. This system imposes an obligation on the consumers to match a predefined share of their electricity consumption with TGCs. The non-compliance fee is also predefined, and must be paid by the consumers independently of the course of the non-compliance. The energy authority can reduce the predefined share, if e.g. the supply of RES-E is very low relative to the demand for TGCs. The noncompliance fee defines a natural upper TGC price. The Danish system operates also with a lower price in order to reduce the investors risk. This guarantee is financed through a fund capturing the non-compliance fees. Figure 26 below illustrates the market equilibrium in a TGC system similar to the Danish for the case with wind turbines as the sole RES-E technology.

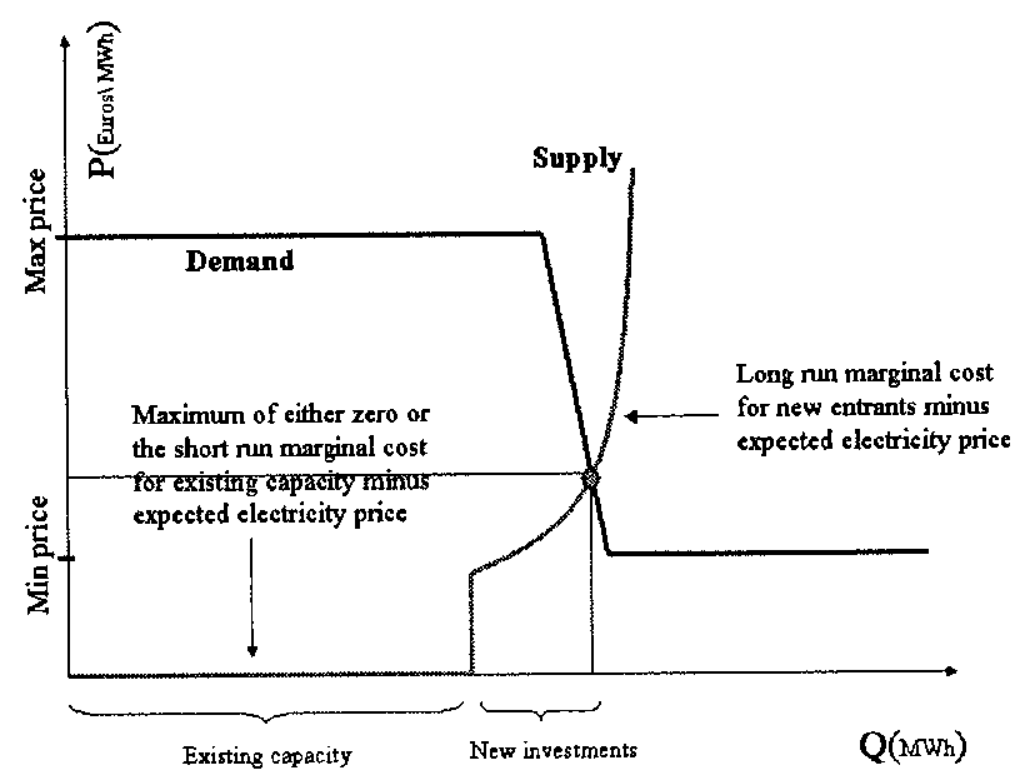

Figure 26. Applying the proposed Danish TGC system to a market with wind turbines as the only RES-E technology. (Source: Lemming (2003)).

The demand curve in Figure 26 reflects the demand for TGCs in a single time period. Since the TGC demand is derived from the demand for electricity and transformed through the compulsory TGC share, the demand curve will be downward sloping and truncated above by the non-compliance fee and below by the guaranteed TGC price. Ideally, the TGC price will be determined from the intersection of the downward sloping part of the demand curve and the long run supply curve for RES-E. Such equilibrium will induce deployment of new RESE reflecting the social cost of the compulsory TGC share.

To analyse a dynamic equilibrium it will be necessary to compensate for problems relating to incomplete information on future TGC prices. Owners of wind turbines are exposed to two main factors of uncertainty, first the number of future competitors and secondly short term variations in the wind conditions. The first factor is generic to almost all trades since it is hard to predict the future aggregated supply curves. Figure 27 below illustrates that even small errors in prediction can imply large variation in the TGC price due to the steep demand curve. Investors wrongly expecting that future long run marginal cost will be high would expect the corresponding TGC price, $\mathrm{P}_{\mathrm{E}}$, to be high also. 


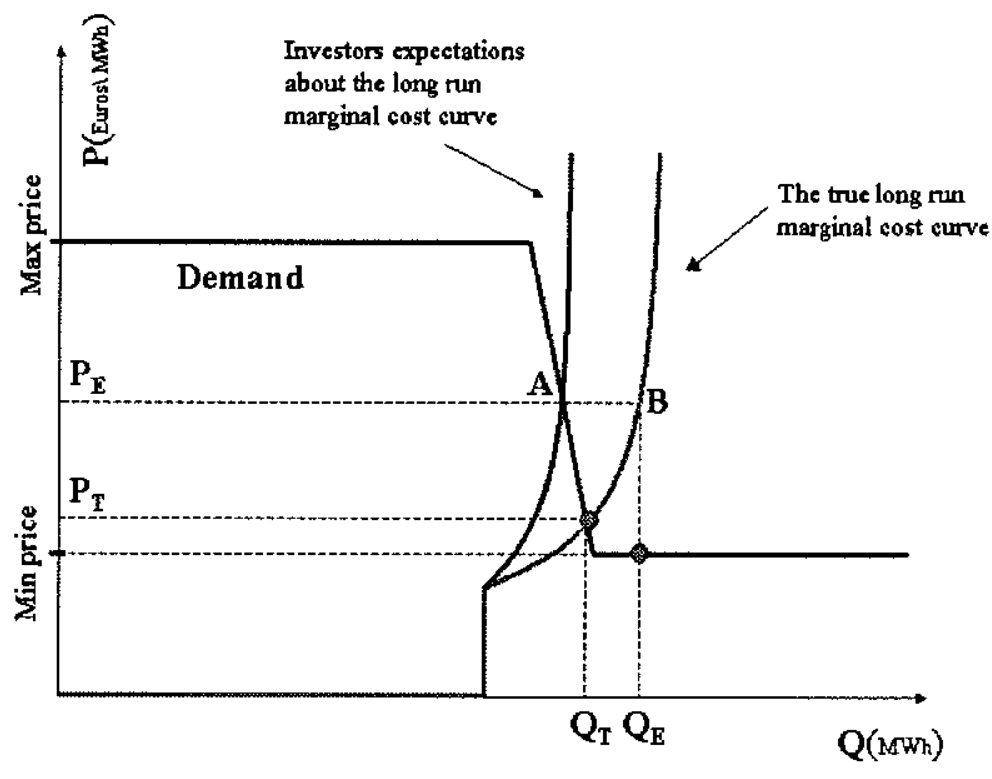

Figure 27. The impact from supply curve uncertainty. (Source: Lemming (2003)

The expected TGC price is derived from the intersection of the supply and the demand curve at point $\mathrm{A}$. After investments have been made the marginal unit will be found at the true cost curve resulting in an excess supply of TGCs. This realisation is off-equilibrium and is illustrated by point B in Figure 27. The TGC price is determined by the demand curve below point B. The full information equilibrium found at the intersection of the demand curve and the true supply curve would still have resulted in deployment of RES-E, but with less deployment and a significantly lower TGC price, $\mathrm{P}_{\mathrm{T}}$.

The second imperfect information problem is the unpredictable wind conditions. Since the demand curve is quite steep, even small variations in the wind causes large variations in the TGC price. Figure 28 illustrates this problem.

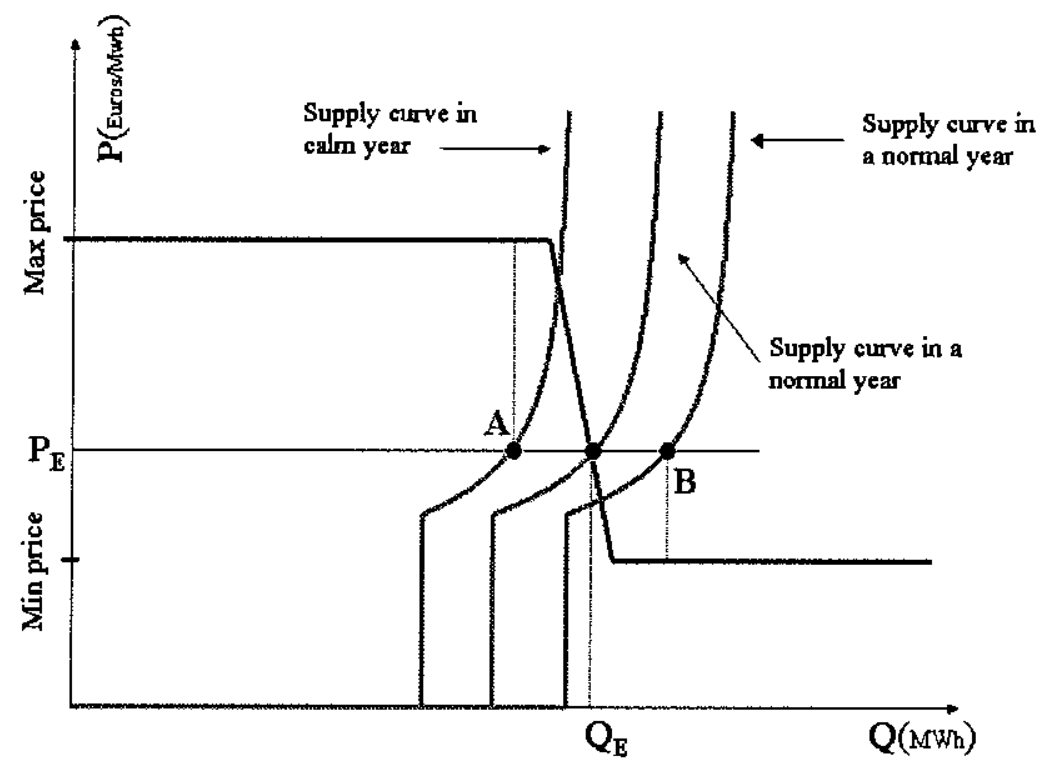

Figure 28. The impact from wind variations on the TGC price. (Source: Lemming (2003)) 
Again, it will be very hard to predict the TGC price. Also, the TGC price might be determined by the price bounds rather than consumer's marginal valuation. Furthermore, if the supply conditions are not common knowledge, suppliers might fail to adapt to these conditions leading to the equililibria such as those denoted A and B in Figure 28. In such cases there will be a loss of economic efficiency.

Although the symptoms derived from the two types of uncertainty described above seem to be the same, namely off-equilibrium production volumes and off-equilibrium prices, they are of quite different nature. The first uncertainty, the capacity uncertainty, relates to the long run supply curve, whereas the second uncertainty, the wind uncertainty, relates to the short run supply curve.

Uncertainties usually imply a risk premium. In the case of wind power it would be natural to ask whether these premia could be reduced, if the supplier were subject to a fixed feed-in tariff instead of a fluctuating market based price. The next two expositions will explore this problem further.

\section{Exposition \# 27: Short term financial risk}

Wind turbines are assumed to operate on competitive electricity markets, which implies that the cost of owning and operating the turbine could never influence the electricity market price in the short run. The investment cost should thus be considered as sunk cost. In fact the operating cost of the wind turbines would always be expected to be less that the electricity market price, implying that the wind turbines will continue to produce, even after a bankruptcy.

Regardless the observation, that owners of wind turbines will never voluntarily reduce generation, they might want to exploit an option to save the derived TGCs to trade them in a later period. Saving the TGCs for later imposes a new uncertainty on the wind turbine owner. Fortunately, this risk exposure might be beneficial to the wind turbine owner.

In a windy year, the wind turbine owner will have a high base income, origination from selling electricity. Due to the corresponding high increase in the stock of not yet traded (both banked and currently produced) TGCs the wind turbine owner will use his option not to market the full production of TGCs. In years with less wind and correspondingly less base income, these unsold TGCs will be marketed in a scarce market to bring the income up. Thus, TGCs have an income stabilising effect, just as claimed in Figures 13 and 14 above.

Had the wind turbine owner been subject to a fixed feed-in tariff system only, he would have been exposed to the full variation in wind. The same could even be a problem with a multiple country TGC scheme, since wind variations would be local phenomena only, leaving the scarcity situation out. In that case, the TGC scheme will be almost as risky as the fixed feedin tariff system.

It should be emphasised that expectations of declining TGC prices in the future will make the RES-E more reluctant to counteract wind variations though banking of TGCs. If the generation of electricity from fossil fuels is penalised for the emissions, the price of TGCs will go down, cf. Figure 11. Not only will the wind turbine owner loose an instrument to counteract income variations, but also will their risk on their base income increase, as the power market price goes up. 


\section{Exposition \# 28: Forward contracts and risk premia}

It is expected that a matured market for TGCs will induce a market for forward contracts also. Lemming (2003) investigates optimal forward contract strategies for wind turbine owners. He assumes the variable cost of operating wind turbines to be negligible, hence the owner focus will be on the revenues only. The wind turbine owner is likely to attempt to reduce his financial risk by proper engagements in forward trades in both electricity and TGCs. The result from the analysis of a wind turbine owner with a sole objective is to minimise the variance on his returns are summarised in Table 13 below.

\begin{tabular}{|c|c|c|c|}
\hline & \multicolumn{2}{|c|}{ TGC trade } \\
\hline & & Spot & Forward \\
\hline \multirow{2}{*}{ 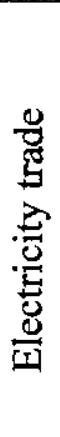 } & 苑 & $\begin{array}{l}\text { Uncontrolled risk exposure. Gains } \\
\text { from the negative covariance be- } \\
\text { tween the prices on the two markets }\end{array}$ & $\begin{array}{l}\text { Similar to a fixed RES-E price sub- } \\
\text { sidy. Only a small contract volume is } \\
\text { recommended due to the inherent } \\
\text { hedging originating from the nega- } \\
\text { tive covariance }\end{array}$ \\
\hline & 㺃 & $\begin{array}{l}\text { No general recommendations. The } \\
\text { optimal strategy relies heavily on } \\
\text { the actual risk parameters }\end{array}$ & $\begin{array}{l}\text { Similar to a fixed feed-in tariff. Full } \\
\text { volume risk. }\end{array}$ \\
\hline
\end{tabular}

Table 13. Revenue variance reducing strategies on forward markets.

Lemming (2003) also discusses the traditional mean-variance trade-off. Financial theory states, that an equal demand for hedging on both the demand side and the supply side implies that the wind turbine owners mean outcome will be unaffected by his trading strategy. If the equality fail to exist the forwards will traded either at discount or at a risk premium. The analysis points to the fact that a compulsory demand for TGCs implies a positive correlation between electricity demand and TGC prices. This correlation will generate a hedging demand on the demand side, leading to a forward price on TGCs in excess of the expected future price.

The optimal strategy will be a result of a trade-off between mean and variance and since there exists an expected gain from issuing forward on TGCs, the wind turbine owners will be likely to carry more risk by trading forwards on TGCs in excess of the strategies described in Table 13 above. 


\section{A case study: Combining international markets}

To further investigate the interactions between energy markets assume the existence of three international markets: (1) a market for electricity; (2) a market for tradable green certificates; and (3) a market for tradable emission permits. This is exactly the set-up in the analysis in Jensen \& Skytte (2001, 2002, 2003b). To complicate things (and to mimic real-life more closely) Hindsberger et al. (2003) assumes these three markets to be organised in intersecting "bubbles". A bubble contains one or more countries, but not necessarily all the countries in the analysis. Furthermore, the three markets will have different bubble structure, e.g. Country A might trade electricity with Countries B and C, but can only trade TGCs with Country B and D, and TEPs with Countries C and D. The Hindsberger et al. (2003) analysis has a very large electricity market, and the approximate boundaries of the TEP and TGC markets are depictied in Figure 29 below.

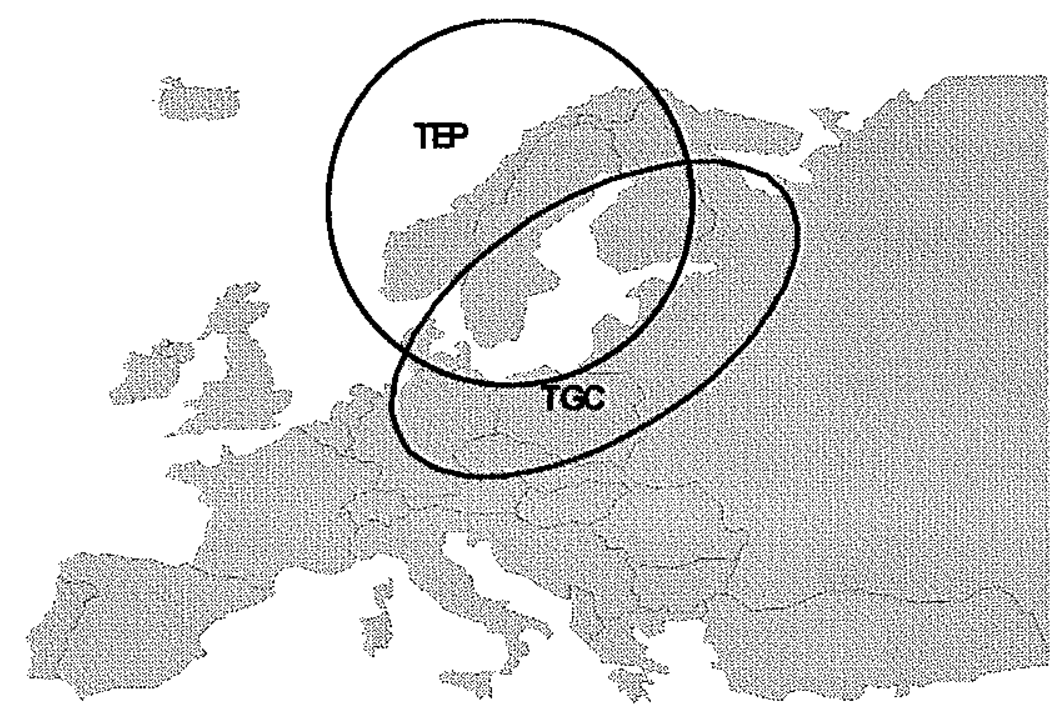

Figure 29. International markets in addition to the electricity market. (Source: Hindsberger et al. (2003)).

\section{Exposition \# 29: Modelling Bubbles and Markets}

Trading of TEP, TGC and electricity will be analysed in a formal model where the corresponding markets do not necessarily coincide. The actual set-up will be the countries near to the Baltic Sea. The model in Hindsberger et al (2003) is a one period static model with investment. The markets for electricity, TEPs and TGCs are assumed to be perfectly competitive in order to model the determination of prices as an optimisation problem. The electricity prices derived will be the true marginal production cost whereas the TEP and TGC prices will be found as shadow prices associated with the constraints related to TEPs and TGCs.

The numerical analysis in Hindsberger et al. (2003) in conducted in the Balmorel model with specific adaptations. The model contains specifications of geographical entities covering most of the countries around the Baltic Sea, and Norway. The bubbles in the analysis are shown in Table 14 below. 


\begin{tabular}{|l|c|c|c|}
\hline Country & Electricity & TGC & TEP \\
\hline Denmark & + & + & + \\
\hline Estonia & + & & \\
\hline Finland & + & + & + \\
\hline Germany & + & + & \\
\hline Latvia & + & & \\
\hline Lithuania & + & & \\
\hline Norway & + & & + \\
\hline Poland & + & & \\
\hline Sweden & + & + & + \\
\hline
\end{tabular}

Table 14. The three bubbles in the analysis.

All countries considered are members of the electricity bubble. Only Denmark, Finland and Sweden are members of all three bubbles. Estonia, Latvia, Lithuania and Poland are only members of the electricity bubble. The model has geographical subdivision of each country, and determines in quarter-of-a-year segments the following entities:

- generation of electricity and heat distinguished by technology and fuel

- consumption of electricity and heat

- electricity transmissions between geographical entities

- investment in generation and transmission capacities

- prices on electricity and heat.

The time segments are obviously too long to catch fluctuations in production and demand, and too short to generate investment within a segment. The chosen time horizon leading up to year 2030 will enhance the reliability of the investments made in the early years in the study.

\section{Exposition \# 30: Scenarios in the Balmorel model}

Following the specification of goals stated in European Commission (2001) ad series of 30 scenarios have been developed in Hindsberger (2003). A specific scenario is related to year 2010 and consists of an emission limit and a RES-E share from Table 15 below.

\begin{tabular}{c|c}
$\begin{array}{c}\text { Nordic } \mathrm{CO}_{2} \text { emission limit } \\
\text { (in Mt) }\end{array}$ & $\begin{array}{c}\text { EU renewable energy } \\
\text { share of demand (in \%) }\end{array}$ \\
\hline 100.6 (TEP0) & 0.0 (TGC0) \\
89.4 & 4.7 \\
78.2 & 9.4 \\
67.1 & 14.2 \\
55.9 (TEP1) & 18.9 \\
& 23.6 (TGC1) \\
\hline
\end{tabular}

Table 15. The 30 scenarios combining an emission level with a RES-E share. (Source: Hindsberger (2003))

The high emission scenario (TEP0) reflects the current emission level in the TEP bubble. The low emission scenario (TEP1) corresponds to the allowed emission from the TEP bubble as specified in the Kyoto targets. The TGCO is a scenario with voluntary deployment of RES-E in the TGC bubble, and the TGCl scenario is derived from the national targets in European 
Commission (2001). Simulation results for the year 2010 show the expected interdependencies.

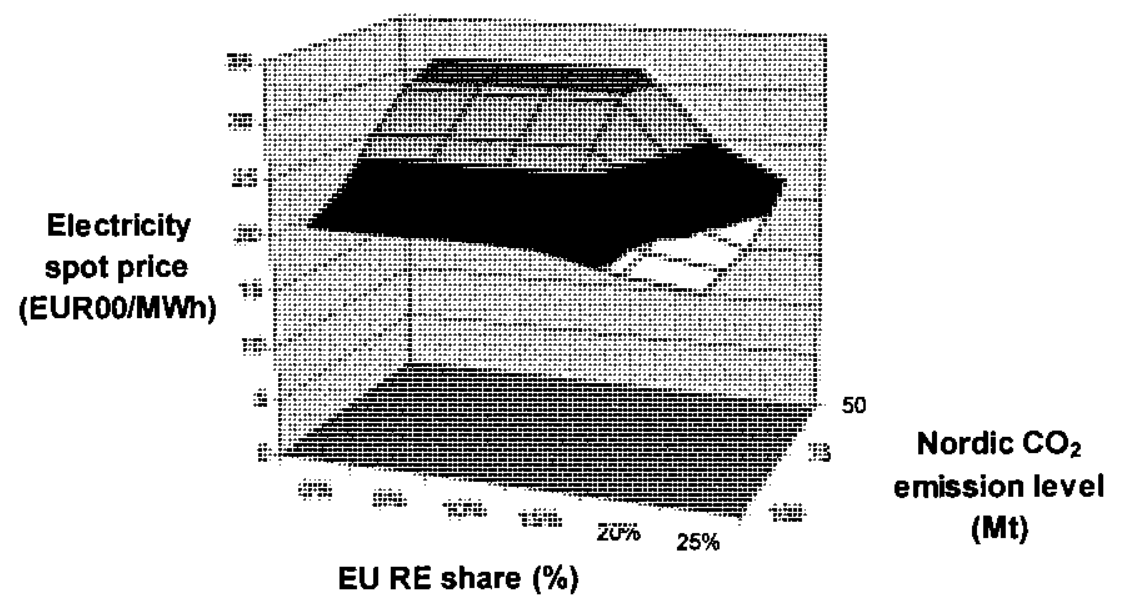

Figure 30. The annual weighted spot price in Eastern Denmark.

Source: Hindsberger et al. (2003))

Figure 30 above shows that increasing the RES-E share will not cause the electricity spot price to increase. This result is valid for all emission levels. Conversely, any restriction on the emission level will cause the electricity spot price to increase. These results are not directly comparable with the Jensen \& Skytte (200I, 2002, 2003b) analysis, since the latter analysis is addressed to consumer prices. The analysis above is consistent with the Jensen \& Skytte analysis in the sense that deployment of RES-E reduces the spot market price on electricity. It is important to notice that the electricity spot market price could remain unchanged with a $25 \%$ emission reduction.

Figure 31 below shows that the TGC price is almost independent of the emission quota. For low RES-E shares, the TGC price will be zero, but will be rapidly increasing for RES-E shares above $15 \%$. At the TGC1 target, $23.6 \%$, the TGC price will be 50 EUR00/MWh.

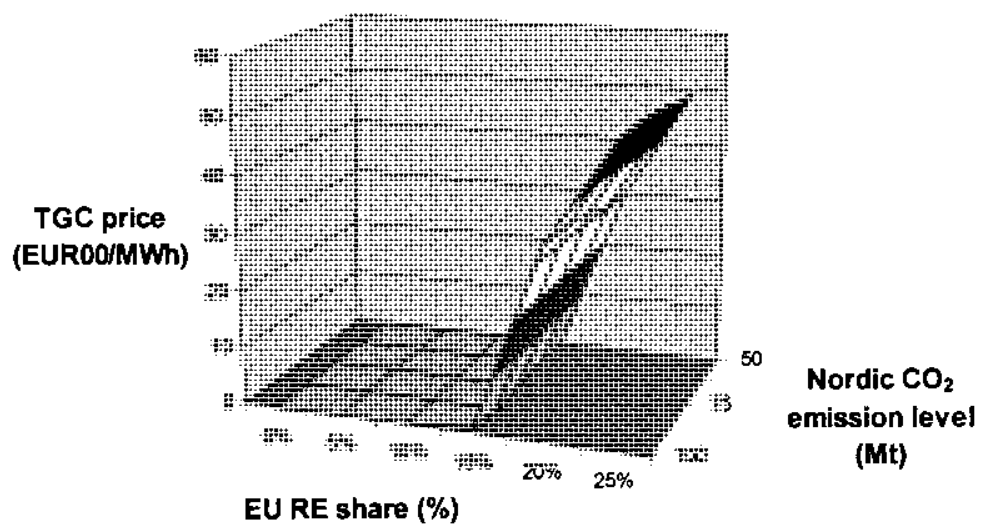

Figure 31. The TGC price in the TCG bubble.

(Source: Hindsberger et al. (2003))

Figure 32 below depicts the results on the TEP price. For RES-E shares above $15 \%$ the TEP become less scarce resulting in a decline in the TEP price. As expected, the TEP price increase as the emission quota becomes more restrictive. With a $20 \%$ RES-E and a $50 \%$ emis- 
sion reduction, the TEP price is only 10 EUR00/t, which is low relative to the proposed EU level for non-compliance fees, but twice as high as the current Danish fee.

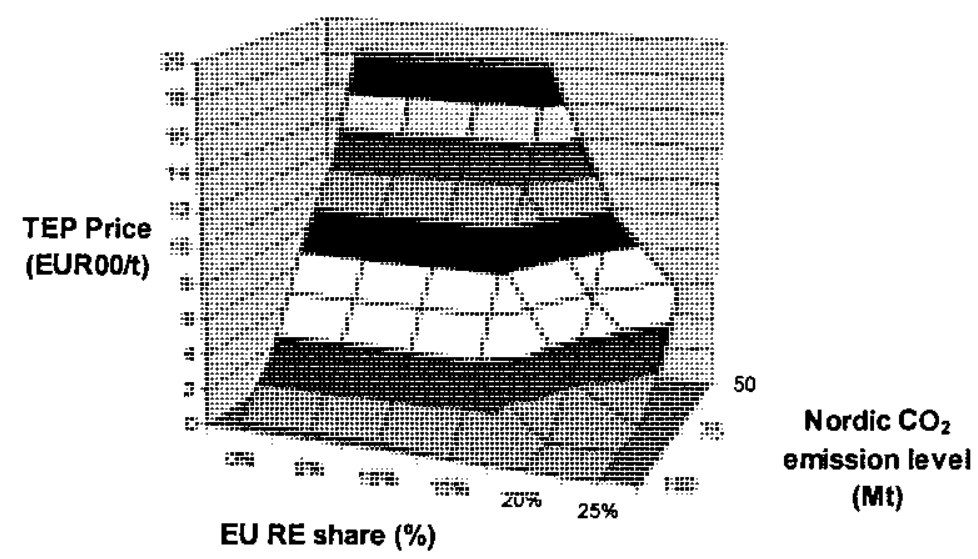

Figure 32. The TEP price in the TEP bubble.

(Source: Hindsberger et al. (2003))

In order to compare with the theoretic results from Jensen \& Skytte (2001, 2002, 2003b), Hindsberger et al. (2003) calculates the aggregate consumer cost by adding the RES-E share multiplied with the TGC price to the spot price. It should be noted that this is not the consumer cost, since taxes are not included. Figure 33 below shows the relations for the Eastern Denmark price zone.

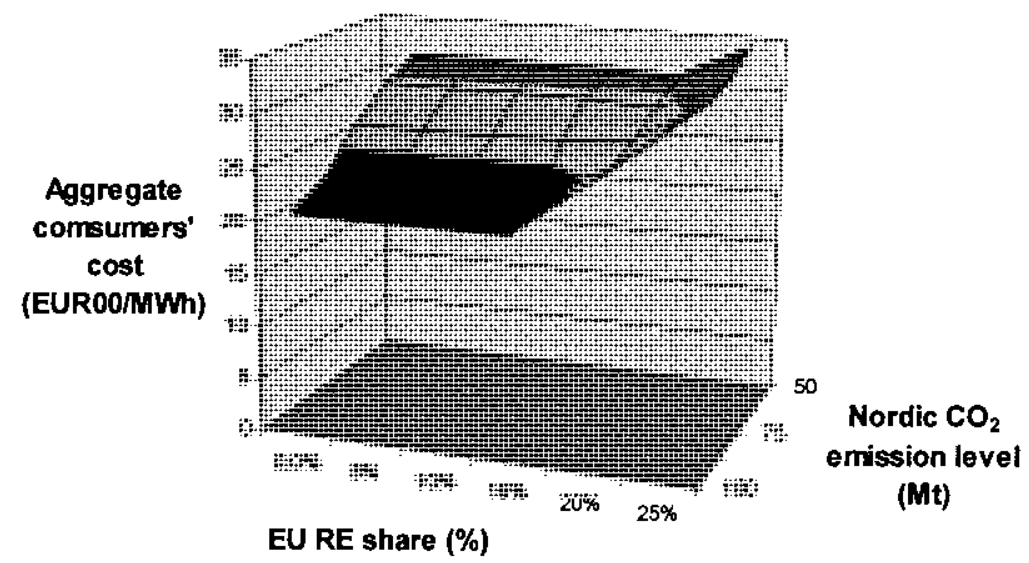

Figure 33. The aggregate consumer cost, i.e. weighted spot and TGC price, in Eastern Denmark. (Source: Hindsberger et al. (2003))

The surprising result predicted in Jensen \& Skytte $(2001,2002,2003 b)$ that consumers might experience a decline in consumer prices is also found in the imperical analysis. At $55 \mathrm{Mt}$ emissions and $18.9 \%$ RES-E share a slight drop in cost is found. Although hardly visible in the figure, the conclusion is strong. The analysis shows that the Danish Kyoto emission goalscould be reached at a cost around 22 EUR00/MWh, which is only $5 \%$ above the initial cost with no restrictions on RES-E and emissions. 


\section{Exposition \# 31: National implications}

Table 16 below contains central results from the empirical analysis. Estonia, Latvia, Lithuania and Poland are only participating in the electricity bubble. For countries in all three bubbles it is clear that RES-E deployment is beneficial to the consumers, and that deployment of RES-E will improve the cost of imposing emission quotas. In Denmark the deployment of RES-E will reduce the cost of reaching the (average) Kyoto emmission target by $90-100 \%$. For countries like Germany and Sweden the cost reduction is even more than $100 \%$. Although related to average target and not the specific national targets, it is quite obvious, that the compliance to the Kyoto protocol calls for RES-E.

\begin{tabular}{|c|c|c|c|c|c|c|c|c|c|c|}
\hline & $\begin{array}{l}\text { Eastem } \\
\text { Denmark }\end{array}$ & $\begin{array}{l}\text { Westem } \\
\text { Denmark }\end{array}$ & Estonia & Finland & Germany & Latvia & Lithuania & Norway & Poland & Sweden \\
\hline TEP0-TGC0 & 21 & 21 & 27 & 19 & 31 & 29 & 32 & 21 & 20 & 21 \\
\hline TEP0-TGC1 & 19 & 18 & 27 & 15 & 23 & 29 & 32 & 17 & 20 & 17 \\
\hline TEP1-TGC0 & 31 & 30 & 27 & 29 & 32 & 29 & 32 & 26 & 20 & 27 \\
\hline TEP1-TGC1 & 22 & 21 & 27 & 19 & 23 & 29 & 32 & 21 & 20 & 20 \\
\hline
\end{tabular}

Table 16. Annual weighted average spot prices 2010 (in EUR00/MWh).

(Source: Hindsberger et al. (2003))

Table 17 below indicates some of the physical implications of the energy policies. In the TEP1-TGC0 scenario, where the energy policy focuses solely on emission quotas, Norway will extend their supply of hydropower. Wind and biomass will only increase slightly in the TEP and TGC bubbles.

TEP1-TGC0 Denmark Finland Germany Norway Sweden

\begin{tabular}{lcccrr}
\hline Wind & 0.7 & 0.0 & 0.0 & 0.0 & 0.0 \\
Hydro & 0.0 & 0.0 & 0.0 & 15.5 & 0.0 \\
Bio + waste & 0.2 & 0.0 & 0.9 & 0.0 & 0.0 \\
Total & 0.9 & 0.0 & 0.9 & 15.5 & 0.0 \\
\hline
\end{tabular}

\begin{tabular}{lccccc} 
& & & & & \\
TEP0-TGC1 & Denmark & Finland & Germany & Norway & Sweden \\
\hline Wind & 9.6 & 6.0 & 10.1 & 0.0 & 2.7 \\
Hydro & 0.0 & 0.0 & 0.0 & 0.0 & 0.0 \\
Bio + waste & 8.5 & 3.9 & 33.1 & 0.0 & 4.8 \\
Total & 18.1 & 9.9 & 43.2 & 0.0 & 7.6
\end{tabular}

\begin{tabular}{lccccc} 
TEP1-TGC1 & Denmark & Finland & Germany & Norway & Sweden \\
\hline Wind & 9.6 & 6.0 & 9.4 & 0.0 & 2.7 \\
Hydro & 0.0 & 0.0 & 0.0 & 0.0 & 0.0 \\
Bio + waste & 8.6 & 8.7 & 28.6 & 0.0 & 5.3 \\
Total & 18.2 & 14.8 & 38.0 & 0.0 & 8.1 \\
\hline
\end{tabular}

Table 17. 2010 production (in TWh) at selected plants in some countries constructed between 2000 and 2010 in three extreme scenarios. (Source: Hindsberger et al. (2003))

Introducing TGCs with a RES-E share near to $25 \%$ - the TGC1 scenario - removes the Norwegian incentive to expand hydropower capacity. In stead, windpower adds up to almost twice the amount of hydropower in the TGC free scenario. Also, biomass and waste incineration becomes large - almost twice as much as wind. Norway deploys neither windpower nor biomass in the TGCl- scenario. 
Focusing on the totals in Table 17 it becomes obvious, that different policy scenarios induce different deployment of generations capacities, and hence different needs for transmission of power.

\section{Exposition \# 32: Welfare Analysis}

Efficient deployment of RES-E does not imply national equilibria between demand and supply of TGCs. Table 18 below depicts the RES-E production result from the four countries in the TGC bubble when the TEP1-TGC1 policy is applied.

\begin{tabular}{lccrr} 
& Denmark & Finland & Germany & Sweden \\
\hline 2010 Demand (TWh) & 41.4 & 83.9 & 641.0 & 167.6 \\
RE target (\%) & 29.0 & 31.3 & 12.5 & 60.0 \\
RE target (TWh) & 12.0 & 26.3 & 80.1 & 100.6 \\
RE production (TWh) & 22.2 & 36.5 & 69.1 & 91.1 \\
RE production surplus (TWh) & 10.2 & 10.2 & -11.0 & -9.5 \\
\hline
\end{tabular}

Table 18. National renewable energy production and demand in 2010 in the TEP1-TGCl case. (Source: Hindsberger et al. (2003))

Both Denmark and Finland will be net exporters of TGCs. The corresponding TGC price will be 50 EUR00/MWh, inducing a yearly inflow of 500 million EUR00 to both Denmark and Finland.

The segmentation of countries in bubbles might also lead to unintended physical spillover effects between tradepartners in different energy policy regimes. An example of such countries could be Sweden, who is member of all three bubbles, and Poland, member of the electricity bubble only. Table 19 below depicts aggregated imports and export for the two countries.

\begin{tabular}{lccrr} 
& \multicolumn{2}{c}{ Poland } & \multicolumn{2}{c}{ Sweden } \\
& Import & Export & Import & Export \\
\hline TEP0-TGC0 & 1.6 & 3.3 & 10.0 & 2.5 \\
TEP1-TGC0 & 0.0 & 8.6 & 20.6 & 12.8 \\
TEP0-TGC1 & 6.4 & 2.7 & 6.4 & 11.4 \\
TEP1-TGC1 & 1.6 & 2.7 & 4.9 & 8.5 \\
\hline
\end{tabular}

Table 19. Imports and exports in Sweden and Poland (TWh).

(Source: Hindsberger et al. (2003))

In the laissez faire scenario, TEP0-TGC0, Poland has a small net export of electricity, 1.7 $\mathrm{TWh}$, whereas Sweden is a large net importer of electricity, 7.5 TWh. The introduction of a Kyoto level emission quota in the TEP bubble will increase the Polish export to $400 \%$, whereas the Swedish net import increases very little. In the scenario with TGCs only Poland now becomes a net importer, 3.7 TWh, whereas Sweden converts to be a net exporter, $5 \mathrm{TWh}$. In severely regulated scenario, TEP1-TGC1, with both TGCs and TEPs Poland regains its net export status, 1.1 TWh, but also Sweden will be a net exporter, 3.6 TWh. This scenario is likely to be preferable to the scenarion with emission quotas only, since Sweden takes over about 7.5 TWh from Poland. 


\section{Policy implications of TGCs}

The main result from the research project is that the deployment of RES-E is likely to be achieved without extra consumer cost through proper use of both Tradable Green Certificates and Tradable Emission Permits. Using these policy instruments correctly, the cost of deployment will be financed through profit absorption among conventional power plants.

The main result relies on the observations in the 32 expositions, each covering relevant issues in the discussion of contemporary, Kyoto and post-Kyoto energy policies. A number of key observations from the preceding expositions will be summarised below.

- A price subsidy to RES-E will be eroded if the supply of conventional electricity is competitive. This is due to the falling marginal cost of the conventional supply.

- Emission taxes and TEP systems induce the same ranking of power plants implying the same emissions from producing a quantity of electricity.

- A TGC system alone makes it hard for RES-E suppliers to appropriate emission gains. A TEP system will facilitate that appropriation. Furthermore, a TEP system will also make it easier to meet both short and long term RES-E deployment goals with a TGC system.

- Applying both TGCs and TEPs might induce synergy effects. Both theory and empirical studies support the existence of a "negative correlation scenario" where the additional cost of using the TEP scheme (see Figure 17) exceeds the additional cost of using the TGC scheme (see Figure 16). In such a scenario the TGCs and TEPs have a positive synergy, enabling emission reductions at no cost to the consumers.

- A EU wide TGC system would be preferable. This future harmonisation should be strongly considered when designing national systems.

- Fixed feed-in tariffs to RES-E exposes wind turbine owners to large variations due to climate variations. Wind turbine owners are likely to gain from a system with compulsory demand for TGCs combined with a forward market on TGCs.

The strong main result of the analysis is due to the fact, that an emission policy will impose an excess cost on all conventional electricity, which constitutes the main part of the electricity supply, whereas a green certificate system only excess cost on the green electricity. Furthermore, the deployment of green electricity will supersede the supply of conventional electricity, hence reducing the spot prices on electricity. 


\section{References}

Danish Energy Authority (2001): Energy Policy Review 2001. www.ens.dk.

European Commission (2001). Directive 2001/77/EC of the European Parliament and Council of 27 September 2001 on the promotion of electricity produced from renewable energy sources in the internal electricity market. Brussels.

Fristrup, P. (2003): Some Challenges Related to Introducing Tradable Green Certificates. Energy Policy, Vol 31(1).

Hindsberger, M., M.H. Nybroe, H.F. Ravn \& R. Schmidt (2003): Co-existence of Electricity, TEP, and TGC Markets in the Baltic Sea Region. Energy Policy, Vol 31(1).

Jensen, S.G. \& Skytte, K.(2001): Emission permits, green certificates, and the power market; Submitted for publication August 2001

Jensen, S.G. \& K. Skytte (2002): Interactions between the power and green certificate market; Energy Policy (2002) Vol 30(5).

Jensen, S.G. \& K. Skytte (2003): Simultaneous attainment of energy goals by use of green certificates and emission permits. Energy Policy, Vol 31(1).

Lemming, J. (2003): Financial Risks for Green Electricity Investors and Producers in a Tradable Green Certificate Market. Energy Policy, Vol 31(1).

Lorenzoni, A. (2003): The Italian Green Certificates Market - Between uncertainty and opportunities. Energy Policy, Vol 31(1).

Morthorst, P.E. (2001): A green certificate market combined with a liberalised power market. Forthcoming.

Morthorst, P.E. (2003): National environmental targets and international emission reduction instruments. Energy Policy, Vol 31(1).

Nielsen, L. \& T. Jeppesen (2003): Tradable Green Certificates in Selected European Countries - Overview and Assessment. Energy Policy, Vol 31(1). 


\section{Publications from the research project}

1. Agerholm, B.; Kristoffersen, H.-E.; Morthorst, P.E.; Nyboe, M.H.; Mortensen, B.C., Promoting renewables through market mechanisms. In: Energy markets: The challenges of the new millennium. Technical papers. (CD-ROM). World energy congress 2001, Buenos Aires (AR), 21-25 Oct 2001. (World Energy Council, Buenos Aires, 2001) vp

2. Andersen, C.; Jensen, T.C.; Morthorst, P.E., Energi. In: Bach, H.; N. Christensen \& P. Kristensen (eds.), Natur og miljø 2001. Påvirkninger og tilstand. (2001) (Faglig rapport fra DMU, 385) p. 35-50

3. Fristrup, P.: Forwards, Futures and Banks - Price stability of Danish RES-E Certificates; Presented at Annual European Energy Conference 2000, Bergen.

4. Fristrup, P.: Some Challenges Related to Introducing Tradable Green Certificates; Energy Policy, Vol 31(1).

5. Hindsberger, M., M.H. Nybroe, H.F. Ravn \& R. Schmidt: Co-existence of Electricity, TEP, and TGC Markets in the Baltic Sea Region; Energy Policy, Vol 31(1).

6. Jensen, S.G. \& K. Skytte: Interactions between the power and green certificate market; Energy Policy (2002) Vol. 30, Issue 5.

7. Jensen, S.G. \& Skytte, K.: Emission permits, green certificates, and the power market; Submitted for publication August 2001

8. Jensen, S.G. \& Skytte, K.: Simultaneous attainment of energy goals by use of green certificates and emission permits; Energy Policy, Vol 31(1).

9. Lemming, J.: Financial Risks for Green Electricity Investors and Producers in a Tradable Green Certificate Market; Energy Policy, Vol 31(1).

10. Morthorst, P.E.: The development of a green certificate market; Energy Policy 28 (2000) pp. 1085-94.

11. Morthorst, P.E.: Commodity trading $-\mathrm{CO}_{2}$ kvoter; SimUniversity, København (DK), 24 Sep 2001. Unpublished

12. Morthorst, P.E.: Energiproduktion og forbrug - miljøkonsekvenser af liberaliseret elmarked; Møde i IDA, København (DK), 13 Dec 2001. Unpublished.

13. Morthorst, P.E.: National environmental targets and international emission reduction instruments; Energy Policy, Vol 31(1).

14. Morthorst, P.E.: Interactions of a tradable green certificate market with a tradable permits market. In: Wind energy for the new millennium. Proceedings. 2001 European wind energy conference and exhibition (EWEC '01), Copenhagen (DK), 2-6 Jul 2001. Helm, P.; Zervos, A. (eds.), (WIP-Renewable Energies, Munich, 2001) p. 23-27

15. Morthorst, P.E. \& J. Fenhann: Regulation perspectives for Danish greenhouse gas emissions. In: Climate change research. Danish contributions. Jørgensen, A.M.K.; Fenger, J.; Halsnæs, K. (eds.), (Danish Meteorological Institute/Gads Forlag, Copenhagen, 2001) p. 377-399

16. Morthorst, P.E.: Interactions of a tradable green certificate market with a tradable permits market. Energy Policy (2001) 29, 345-353

17. Nielsen, L. \& T. Jeppesen: Tradable Green Certificates in Selected European Countries Overview and Assessment; Energy Policy, Vol 31(1). 
Title and authors

Green certificates and tradable permits

Peter Fristrup (ed.)

Department or group

Date

Systems Analysis Department

December 2002

\begin{tabular}{llll}
\hline Pages & Tables & llustrations & References \\
48 & 19 & 33 & 12 \\
\hline
\end{tabular}

Abstract (max. 2000 characters)

This report provides a number of results on the interaction between an international market for green certificates market and other energy and environmental policies. The main conclusion is that the deployment of RES-E is likely to be achieved without extra consumer cost through proper use of both Tradable Green Certificates and Tradable Emission Permits. Using these policy instruments in concerted action, the cost of deployment will most likely be financed through profit reduction at conventional power plants.

2 copies: Information Service Department 